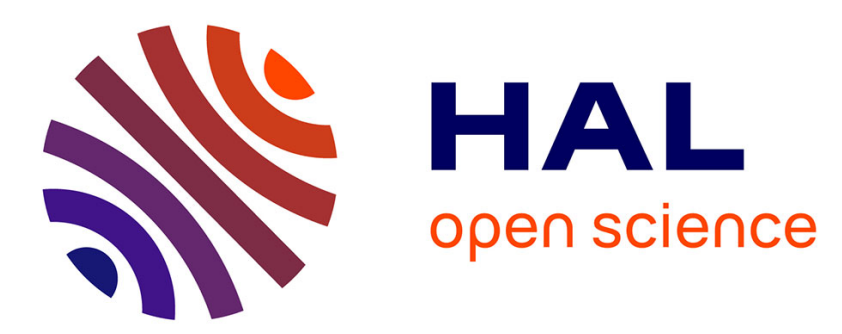

\title{
A numerical simulation of Hurricane Bret on 22-23 August 1999 initialized with airborne Doppler radar and dropsonde data
}

Olivier Nuissier, Robert Rogers, Franck Roux

\section{- To cite this version:}

Olivier Nuissier, Robert Rogers, Franck Roux. A numerical simulation of Hurricane Bret on 22-23 August 1999 initialized with airborne Doppler radar and dropsonde data. Quarterly Journal of the Royal Meteorological Society, 2005, 131, pp.155-194. 10.1256/qj.02.233 . hal-00135876

\section{HAL Id: hal-00135876 https://hal.science/hal-00135876}

Submitted on 8 Feb 2022

HAL is a multi-disciplinary open access archive for the deposit and dissemination of scientific research documents, whether they are published or not. The documents may come from teaching and research institutions in France or abroad, or from public or private research centers.
L'archive ouverte pluridisciplinaire HAL, est destinée au dépôt et à la diffusion de documents scientifiques de niveau recherche, publiés ou non, émanant des établissements d'enseignement et de recherche français ou étrangers, des laboratoires publics ou privés.

\section{(ㄷ)(1) $\$$}

Distributed under a Creative Commons Attribution - NonCommerciall 4.0 International 


\title{
A numerical simulation of Hurricane Bret on 22-23 August 1999 initialized with airborne Doppler radar and dropsonde data
}

\author{
By OLIVIER NUISSIER ${ }^{1}$, ROBERT F. ROGERS ${ }^{2}$ and FRANK ROUX ${ }^{1} \dagger$ \\ ${ }^{1}$ Laboratoire d'Aérologie, Université Paul Sabatier, Toulouse, France \\ ${ }^{2}$ NOAA/AOML Hurricane Research Division, Miami, Florida, USA
}

\begin{abstract}
This study concerns the simulation of Hurricane Bret on 22-23 August 1999 with the MésoNH nonhydrostatic, two-way interactive, quadruple-nested grid mesoscale model. A $30 \mathrm{~h}$ integration, from 0000 UTC 22 August to 0600 UTC 23 August, covers the period of maximum intensity over the Gulf of Mexico and landfall over Texas. Special attention is paid to the initial conditions from which the model is integrated. A balanced vortex, derived from airborne Doppler radar data, is used to replace the ill-defined cyclone in the large-scale analysis. In addition, the analysed humidity field over the Gulf of Mexico is modified in accordance with specific dropsonde observations.

A comparison between the simulated storm track and intensity for three different numerical experiments shows that the inclusion of the radar-derived vortex and high spatial resolution are necessary to obtain a realistic simulation. After an initial period of adjustment, the simulation with the inserted radar-derived vortex and high resolution produces a storm only $10 \mathrm{hPa}$ weaker than the observation after $24 \mathrm{~h}$, compared to the control run that is nearly $50 \mathrm{hPa}$ weaker at the same time. The characteristics of this simulated storm at its mature stage are then presented, with particular emphasis on the processes that modulate the intensity of the inner core region.
\end{abstract}

KEYWORDS: Initialization, Non-hydrostatic numerical models, Tropical cyclones, Vortex Rossby waves

\section{INTRODUCTION}

Tropical cyclones are complex meteorological phenomena which cannot be understood without considering a wide range of spatial scales and physical processes. On the one hand, the presence of a warm sea surface and deep ocean mixed layer, as well as high relative humidity, weak wind shear, convergence in the low levels and divergence aloft, are mainly controlled by large-scale oceanic and atmospheric processes which determine the possibilities of storm development and decay (e.g. Emanuel 1986). On the other hand, three-dimensional processes related to deep convection in the inner region of tropical cyclones, which occur at much smaller scales, control the evolution of storm intensity and act upon its propagation (e.g. Willoughby et al. 1982; Peng and Williams 1990). A comprehensive description of all these aspects is beyond the reach of present observational capabilities, and it is only recently that fully three-dimensional non-hydrostatic multi-nested numerical models with realistic physical parametrizations (and the necessary computing resources) have become available to simulate these different aspects. In this approach, the various observations, both from operational networks and from dedicated research programmes, are used to better specify the initial conditions from which the model is integrated and to check the reliability of the simulated fields.

Following the pioneering work of Anthes (1972), Jones (1977), and Kurihara and Bender (1982), Tripoli (1992) was the first to obtain a realistic description of the inner core and rainbands of a hurricane with a non-hydrostatic model. Since then, many numerical studies have been performed that study various aspects of storm structure and its interactions with the environment. Liu et al. (1997) used the non-hydrostatic triple nested (horizontal grid sizes of 54, 18 and $6 \mathrm{~km}$ ) Pennsylvania State University/National

$\dagger$ Corresponding author: Laboratoire d'A'erologie (UMR 5560 CNRS - Universite' Paul Sabatier),

Toulouse, France. e-mail: frank.roux@ aero.obs-mip.fr 
Center for Atmospheric Research fifth generation Mesoscale Model (MM5) to simulate Hurricane Andrew (1992) over a $72 \mathrm{~h}$ integration from the storm's initial development to landfall over south Florida. In a series of papers, Liu et al. $(1997,1999)$ and Zhang et al. $(2000,2001,2002)$ have analysed the inner core of the storm, through the study of kinematic and thermodynamic characteristics, vertical force balance, budgets of radial and angular momentum, supergradient flows and forces in the eyewall, budgets of potential temperature, humidity and equivalent potential temperature. Wang (2001, 2002a,b) also demonstrated the capability of his triple nested movable-mesh primitiveequation model to simulate many aspects of the tropical cyclone, especially the inner core structure and both the inner and outer spiral rainbands. Braun (2002) analysed a $72 \mathrm{~h}$ numerical simulation of Hurricane Bob (1991) using MM5 with a quadruple grid nesting (36, 12, and $4 \mathrm{~km}$ for 24 hours, and $1.33 \mathrm{~km}$ for 6 hours). The timeaveraged structure of the storm's inner core was characterized by a wave number-one asymmetry, strongly modified by a rotating wave number-two asymmetry consistent with a vortex Rossby wave. He also found that the eyewall updraughts were episodically fed by warm air drawn from the eye and, unlike Zhang et al. (2000), that the dynamic pressure perturbations forced negatively buoyant air out of the boundary layer, after which thermal buoyancy (with respect to an environment including the warm core) was responsible for the upward acceleration. Rogers et al. (2003) performed a highresolution MM5 simulation of Hurricane Bonnie (1998) using an auto-movable-mesh scheme, and showed that, consistent with observational and theoretical studies, the evolution of azimuthal asymmetries in low-level convergence, vertical motion, and inner core convection was related to the magnitude and direction of the vertical shear of the environmental wind.

One major drawback of many of these studies is the fact that the initial vortex, usually obtained from global analyses, is often ill-defined, too weak, and sometimes misplaced, leading to problems in the subsequent simulation of storm track, structure, and intensity. To improve the specification of the initial vortex, Kurihara et al. (1993) proposed a scheme in which the crudely resolved tropical cyclone in the large-scale analysis is replaced by a vortex that is properly specified for use in the prediction model. Alternatively, Zou and Xiao (2000) developed a 'bogus-data assimilation' (BDA) scheme, which generates a dynamically and physically consistent initial condition describing the dynamic and thermodynamic structure of the hurricane vortex by fitting the MM5 forecast model to a specified bogus surface low. An application to Hurricane Felix (1995) during its mature stage with triple grid nesting $(90,30$ and $10 \mathrm{~km})$ shows that this approach can recover the main features of a mature hurricane, and that the prediction of track and intensity is improved. Applying this technique to Hurricane Fran (1996), Xiao et al. (2000) showed that, despite producing satisfying results in landfall location, the simulated track and intensity are sensitive to the size of the initial bogus vortex. Pu and Braun (2001) found that only when the bogus sea-level pressure and wind information are assimilated together does a model produce a vortex that results in significant improvements to forecasts of both intensity and track. Other techniques have used various platforms for remotely sensed data to improve the specification of the initial vortex. Zhu et al. (2002) used the Advanced Microwave Sounding Unit to derive a tropical cyclone's wind and temperature fields from the nonlinear balance and omega equations, and found that incorporation of these data improved their simulation of Hurricane Bonnie (1998). Pu et al. (2002) demonstrated that incorporation of surface rainfall data derived from the Tropical Rainfall Measuring Mission Microwave Imager with a bogus vortex is beneficial, because it improves the simulation of the asymmetric storm structure. 
Therefore, it is now widely recognized that using all the available datasets is a necessary condition for advancing numerical prediction of tropical cyclone intensity and rain. However, not every non-hydrostatic nested-grid three-dimensional mesoscale model has an adjoint model, necessary to minimize the cost function defined in BDA (Zou and Xiao 2000) for the purpose of obtaining the optimum hurricane initial conditions. Moreover, high-resolution atmospheric data (e.g. from in-flight aircraft measurements, dropsondes, coastal and airborne Doppler radars) have great potential to initialize the inner core circulation, but generally they are not assimilated in operational weather prediction models.

The purpose of this paper is to show that airborne Doppler radar data can be used to define a 'specified vortex' for model initialization which, with the addition of a correction of the analysed mesoscale humidity field with dropsonde data, leads to a substantial improvement of the simulated storm with regard to track, structure and intensity without such data assimilation. Although meteorological radar data have been used in initialization and data assimilation experiments with mesoscale models (e.g. Wang and Warner 1988; Aonashi 1993; Takano and Segami 1993; Bielli and Roux 1999; Rogers et al. 2000), to our knowledge no previous attempt has been made to use such observations to initialize a numerical simulation of a tropical cyclone.

Section 2 briefly reviews the main characteristics of the MésoNH non-hydrostatic nested-grid numerical model. Section 3 gives an overview of Hurricane Bret (1999) and of the airborne Doppler radar and dropsonde observations. Section 4 presents the initial fields from an operational large-scale analysis, and the available observations of Bret on 21-23 August 1999. Section 5 compares the performances of different numerical experiments in simulating the storm track, then discusses the characteristics of azimuthal mean and asymmetric fields in the inner core of the hurricane produced by the highresolution simulation. Conclusions and some perspectives for future work are discussed in section 6 .

\section{MODEL DESCRIPTION}

A three-dimensional, two-way interactive, quadruple-nested version of the French MésoNH non-hydrostatic mesoscale numerical model (Lafore et al. 1998) has been used for the simulation of Hurricane Bret from 22-23 August 1999. MésoNH is the result of a joint effort by Centre National de Recherches Météorologiques (Météo-France) and Laboratoire d'Aérologie (Centre National de la Recherche Scientifique-Université Paul Sabatier). It is based on the Lipps and Hemler (1982) modified anelastic system, in order to avoid problems due to the fast propagation of acoustic waves and to allow a correct representation of the gravity-wave momentum flux in the upper atmosphere. The basic atmospheric variables are temperature, pressure, and densities of dry and moist air. The prognostic variables are the three Cartesian components of velocity, the dry potential temperature and the different water mixing ratios.

The system of equations includes: (i) the anelastic approximation for air mass conservation; (ii) the conservation of dry air momentum, including the Coriolis force due to the earth's rotation and subgrid-scale turbulent diffusion; (iii) the thermodynamic equation including diabatic effects (latent-heat release, radiation, diffusion); (iv) the conservation of water quantities. Pressure perturbations are determined by solving the elliptic equation obtained by combining air mass and momentum conservation equations.

The explicit microphysical scheme takes into account liquid and ice phases of cloud and precipitation (Stein et al. 2000). It predicts the mixing ratios of six atmospheric 


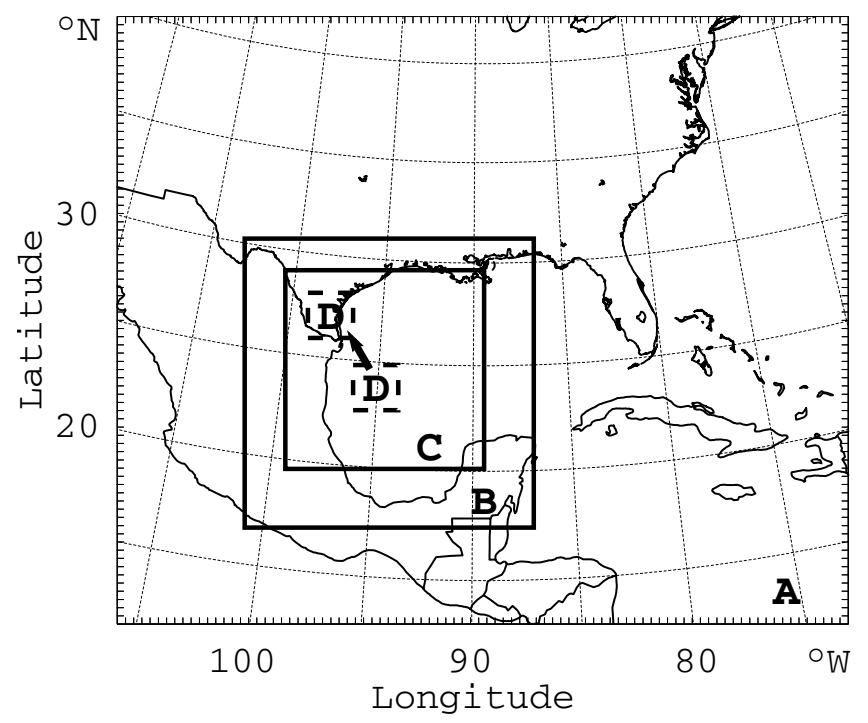

Figure 1. The four nested horizontal domains used in the MésoNH simulations. Domain A has $90 \times 75$ grid points and a horizontal grid spacing of $45 \mathrm{~km}$. Domain B has $108 \times 108$ grid points and a horizontal grid spacing of $15 \mathrm{~km}$. Domains C and D both have $180 \times 180$ grid points with horizontal grid spacings of 5 and $1.67 \mathrm{~km}$, respectively.

water categories: water vapour, non-precipitating cloud water, rain, non-precipitating ice, snow aggregates, and graupel. Precipitating particles are assumed to obey generalized gamma distributions. The mass-diameter and fallspeed-diameter relationships are expressed as power laws adapted to each type of hydrometeor. Parametrizations of the different microphysical processes (e.g. nucleation, conversion, riming, sedimentation) represent the multiple interactions operating between the various water species.

The Gal-Chen and Sommerville (1975) vertical coordinate is used to take into account the earth's sphericity and local orography. In our simulation there are 46 vertical levels; the spacing between them varies continuously with altitude, from $100 \mathrm{~m}$ close to the surface to $600 \mathrm{~m}$ aloft. The top of the domain is at $20 \mathrm{~km}$ altitude, and Rayleigh damping is progressively applied above $15 \mathrm{~km}$ altitude (i.e. the last eight levels) to the perturbations of wind components and thermodynamical variables with respect to their large-scale values in order to prevent spurious reflections from the model upper boundary. The spatial discretization is done according to a ' $\mathrm{C}$-grid' in the Mesinger and Arakawa (1976) terminology, both on the horizontal and on the vertical, and it is based on second-order finite differences. The time discretization is explicit and follows the 'leap-frog' scheme.

The two-way interactive grid-nesting technique (Clark and Farley 1984) allows up to eight nested models to be run simultaneously. The only limitation is that the ratios of temporal and spatial resolutions between the coarse- and fine-mesh models must be integers. For this study, the model had four nested domains A, B, C and D in the horizontal plane, with $90 \times 75,108 \times 108,180 \times 180$ and $180 \times 180$ grid points, and horizontal grid spacings of 45, 15, 5 and $1.67 \mathrm{~km}$, respectively (Fig. 1). As the relative positions of the nested domains in the MésoNH model are fixed during the simulation, the innermost domain D (1.67 km horizontal resolution) had to be set 'manually' at different locations within domain $\mathrm{C}(5 \mathrm{~km})$ so as to follow the simulated tropical cyclone propagation. For homogeneity reasons, the new $1.67 \mathrm{~km}$ grid was initialized using data 
from the $5 \mathrm{~km}$ grid, with a large overlap of the previous $1.67 \mathrm{~km}$ zone. Although efficient, this procedure inevitably induces some smoothing along the boundaries of the $1.67 \mathrm{~km}$ grid after each grid move.

In this study, the three-dimensional turbulence scheme of Cuxart et al. (2000) has been used with a mixing length closure, taking into account possible anisotropies of the grid. Air-sea fluxes of sensible and latent heat are calculated through aerodynamic formulae with wind-dependent exchange coefficients (Dupuis et al. 1997). The radiation scheme calculates the radiative fluxes, considering absorption-emission of long-wave radiation, and reflection, scattering and absorption of solar radiation by the earth's atmosphere and surfaces (Morcrette 1989). Convective parametrization is based on the Kain and Fritsch $(1990,1993)$ scheme, with closure based on static stability, parametrization of moist downdraughts, detrainment of hydrometeors and realistic computation of entrainment through a buoyancy mechanism. Bechtold et al. (2001) have shown that for MésoNH a grid spacing of $5 \mathrm{~km}$ is a threshold above which convective parametrization must be used. In this present study the convection scheme is activated only for domains A and B (Fig. 1), where horizontal resolution is coarser than this limit.

\section{OVERVIEW OF HURRICANE BRET}

\section{(a) Storm history}

The 1999 hurricane season was very active compared to the mean values for 195090, with 12 named storms among which five reached category four on the SaffirSimpson scale (Lawrence et al. 2001). Bret was among these intense hurricanes but, fortunately, it made landfall along a sparsely populated section of the south Texas coast and caused no casualties.

Both a tropical wave, which moved from the African coast to the tropical eastern Atlantic Ocean on 5 August 1999, and an upper-level low over the north-western Caribbean Sea contributed to the formation of a disturbance on 18 August. As a closed circulation was observed during a reconnaissance mission, the system was upgraded to a tropical depression at $1800 \mathrm{~h}$ (all times are UTC) 18 August over the Bay of Campeche. Due to strong vertical wind shear caused by an upper-level trough over the western Gulf of Mexico, the depression did not strengthen rapidly. But once the trough moved away toward the east, the depression reached tropical storm status late on 19 August, whilst beginning to move slowly northward. With the decrease of vertical wind shear Bret became more organized, and it steadily strengthened to a category-four hurricane with $62 \mathrm{~m} \mathrm{~s}^{-1}$ surface winds and $944 \mathrm{hPa}$ surface pressure on the morning of 22 August, when it was approaching the southern Texas coast near Brownsville.

As seen on a National Oceanic and Atmospheric Administration (NOAA)-12 AVHRR visible image over the western Gulf of Mexico at $2320 \mathrm{~h} 21$ August (Fig. 2(a)), Bret was a relatively small but well-organized and rather intense storm, with a ring of deep convective clouds enclosing the eye. A large plume of high cirrus clouds extended northward and eastward, indicative of the upper-level divergence associated with a rain band to the north of the eyewall. The horizontal reflectivity composite, obtained from airborne radar observations between 2250 and $2305 \mathrm{~h} 21$ August by the NOAA Hurricane Research Division (HRD), reveals that Bret had a well-defined, closed eyewall of about $35 \mathrm{~km}$ diameter with the highest reflectivity values on its north-western side, and a band of relatively strong intensity of $150-200 \mathrm{~km}$ in length about $60 \mathrm{~km}$ north of the storm centre (Fig. 2(b)).

On 22 August, in response to a weak mid-tropospheric ridge over the north-west Gulf of Mexico and a mid-tropospheric cyclonic circulation over the Rio Grande valley, 
(a) 990821_2320

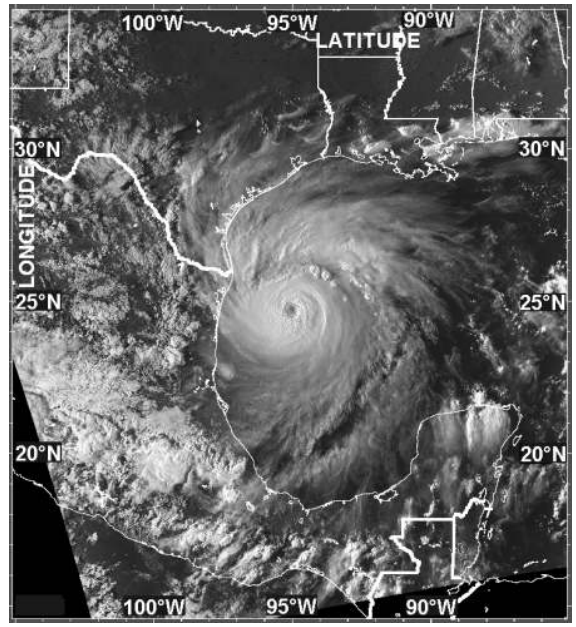

(c) 990822_2258

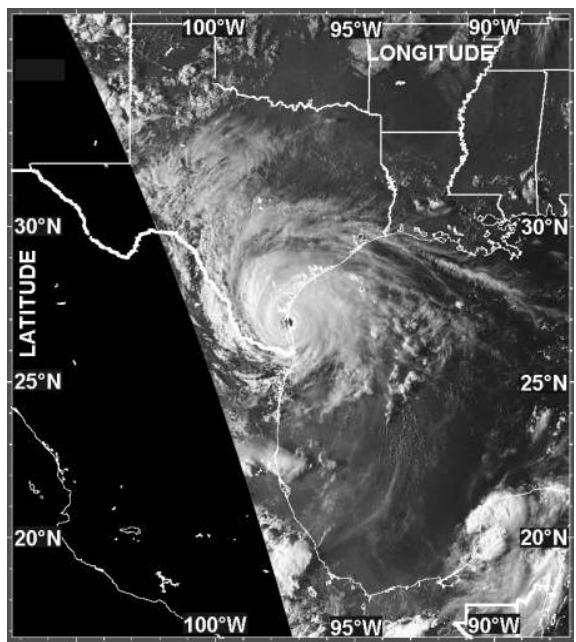

(b) 990821_2250-2305

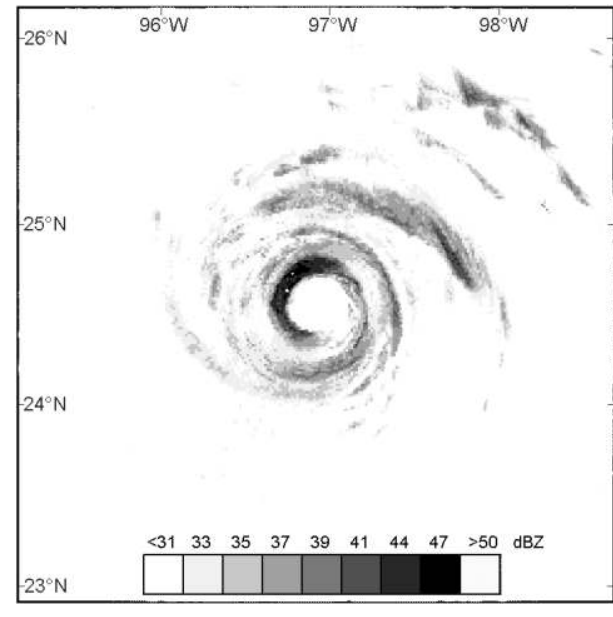

(d) 990822_2030-2059

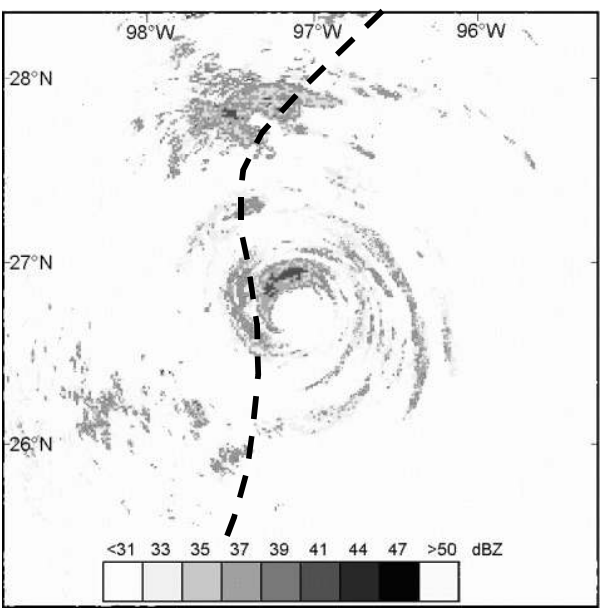

Figure 2. Hurricane Bret on 21 and 22 August 1999: (a) NOAA-12/AVHRR visible channel at 2320 UTC 21 August; (b) reflectivity composite from the lower fuselage radar of NOAA WP-3D aircraft from 2250 till 2305 UTC 21 August; (c) as in (a) except for 2300 UTC 22 August; (d) as in (b) except for 2030-2059 UTC 22 August, the dashed line denotes the Texas coast. (Figs. 2(a) and (c) are reproduced with permission from Steven Babin and Ray Sterner of The John Hopkins University Applied Physics).

Bret turned north-westward. The NOAA/HRD airborne radar reflectivity composite from 2030 till $2059 \mathrm{~h} 22$ August (Fig. 2(d)) shows that the diameter of the storm eye had shrunk to about $25 \mathrm{~km}$. The eyewall and rainbands were more asymmetric, with stronger reflectivity values on the north-north-western side of the storm. Bret made landfall over the Texas coast between Brownsville and Corpus Christi at 0000 h 23 August, with estimated sustained surface winds of $50 \mathrm{~m} \mathrm{~s}^{-1}$ (Fig. 2(c)); it then moved westward and finally dissipated on 25 August over the high terrain of north central Mexico. Below, we examine the model performance in simulating the storm track, structure, and intensity during the period from 0000 to 1800 h 22 August 1999. 


\section{(b) The airborne Doppler radar and dropsonde observations}

The annual NOAA/HRD Field Program collects data to improve the understanding of the changes in tropical cyclones' tracks, structures, and intensities, and how these changes relate to their atmospheric and oceanic environment. Different airborne experiments are conducted every year in tropical cyclones over the western Atlantic Ocean, the Caribbean Sea, the Gulf of Mexico and, sometimes, the eastern Pacific Ocean. In 1999, the objective of the Extended Cyclone Dynamics Experiment was to sample the inner core region of hurricanes, in order to better understand how the interactions between the vortex and the synoptic-scale environment control the hurricane intensity and motion.

Such an experiment was conducted for Hurricane Bret on 21 August. One NOAA WP-3D (P3) aircraft obtained detailed information in the inner core region with Doppler radar, and the NOAA Gulfstream IV-SP (G-IV) aircraft collected vertical profiles of wind, temperature and humidity by launching Global Positioning System dropsondes within about $1500 \mathrm{~km}$ of the hurricane centre. Four successive $280 \mathrm{~km}$ radial legs were flown by the P3 at $4200 \mathrm{~m}$ altitude across the storm centre: east to west from 2005 till $2040 \mathrm{~h}$, south-west to north-east from 2054 till $2126 \mathrm{~h}$, north to south from 2138 till $2215 \mathrm{~h}$, and south-east to north-west from 2225 till $2310 \mathrm{~h}$. The radius-altitude distribution of the azimuthally averaged reflectivity values reveals an outward tilt of the reflectivity maximum, located at $20 \mathrm{~km}$ radius near the surface, and $30 \mathrm{~km}$ radius at $10 \mathrm{~km}$ altitude (subsection 4(c)); note that, since reflectivity is a logarithmic quantity, the reflectivity-derived precipitation contents are averaged, then transformed into equivalent reflectivity values). The secondary maximum below $5 \mathrm{~km}$ altitude at $70-95 \mathrm{~km}$ radii is related to the outer convective band (Fig. 2(b)).

From 1751 h 21 August to 0143 h 22 August, the G-IV sampled the environment around Bret by releasing dropsondes over the Gulf of Mexico (subsection 4(a)). These data are assimilated into objective statistical and dynamical hurricane prediction models, and they can help to substantially improve short and medium term (24-72 hours) prediction of tropical cyclone tracks (Franklin and DeMaria 1992). However, these specific data are not systematically assimilated in the operational analysis of global circulation models. The availability of dropsonde data offers an opportunity to study vortex interaction with the environmental wind shear and the thermodynamic structures that are hypothesized to control hurricane intensification. Another issue that can be addressed by using the dropsonde data is the importance of accurately capturing the moisture field in the environment of tropical cyclones. Advection of dry air at low levels could decrease the high equivalent potential temperature $\left(\theta_{\mathrm{E}}\right)$ inflow towards the core region, while the presence of dry air in the mid-levels could generate downdraughts which would bring colder air into the boundary layer. Both factors are detrimental to tropical cyclones and favour their decay.

\section{INITIAL FIELDS AND EXPERIMENTAL CONDITIONS}

\section{(a) European Centre for Medium-range Weather Forecasts analyses}

The MésoNH model was initialized using the European Centre for Medium-range Weather Forecasts (ECMWF) analysis at $0000 \mathrm{~h} 22$ August. The equivalent horizontal truncation of the T-213 spectral ECMWF model in 1999 is equivalent to a resolvable scale (half wavelength) of about $90 \mathrm{~km}$, and the horizontal resolution of the gridded fields is about $60 \mathrm{~km}$. This large-scale analysis displays conditions in the environment of Hurricane Bret that are favourable for tropical cyclone intensification. The storm was embedded in an area of low vertical wind shear $\left(<5 \mathrm{~m} \mathrm{~s}^{-1}\right.$ between 850 and $300 \mathrm{hPa}$, Fig. 3(a)), and high sea surface temperature (SST $>28.5^{\circ} \mathrm{C}$, Fig. 3(b)). Both factors 


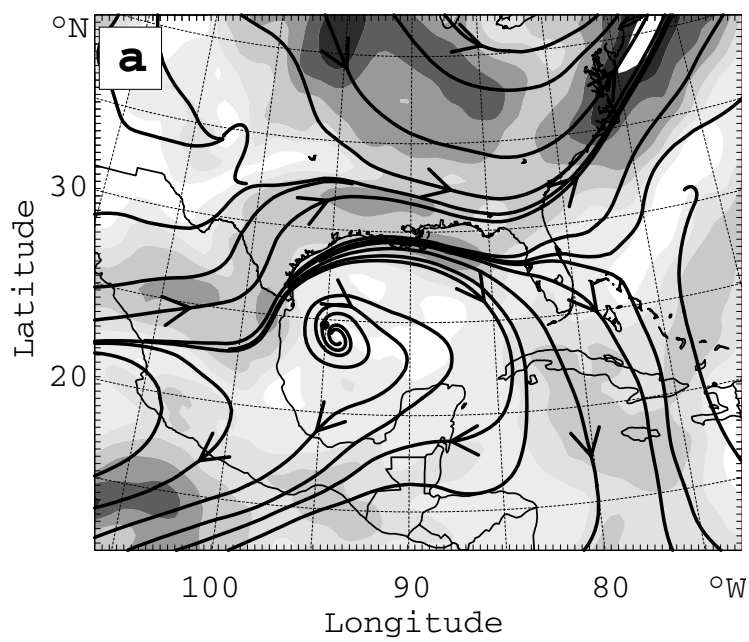

Vertical wind shear
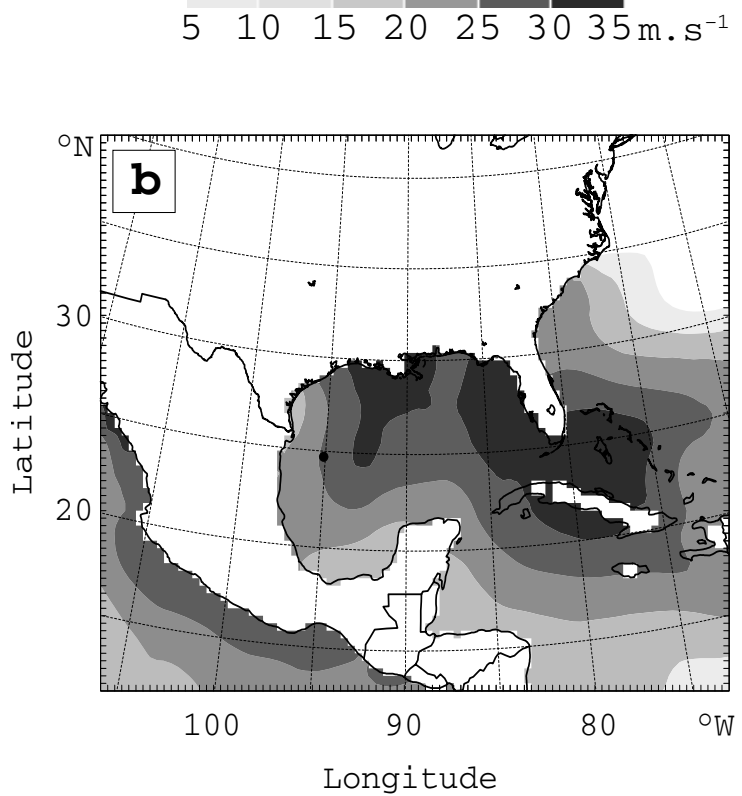

SST

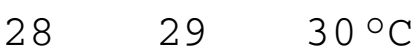

Figure 3. (a) Vertical wind shear (grey scale) between model $\sigma$-levels 12 and 32 (1500 and $12000 \mathrm{~m}$ above mean sea level, without orography), and surface synoptic flow (streamlines); (b) sea surface temperature from the ECMWF global analysis at 0000 UTC 22 August. 

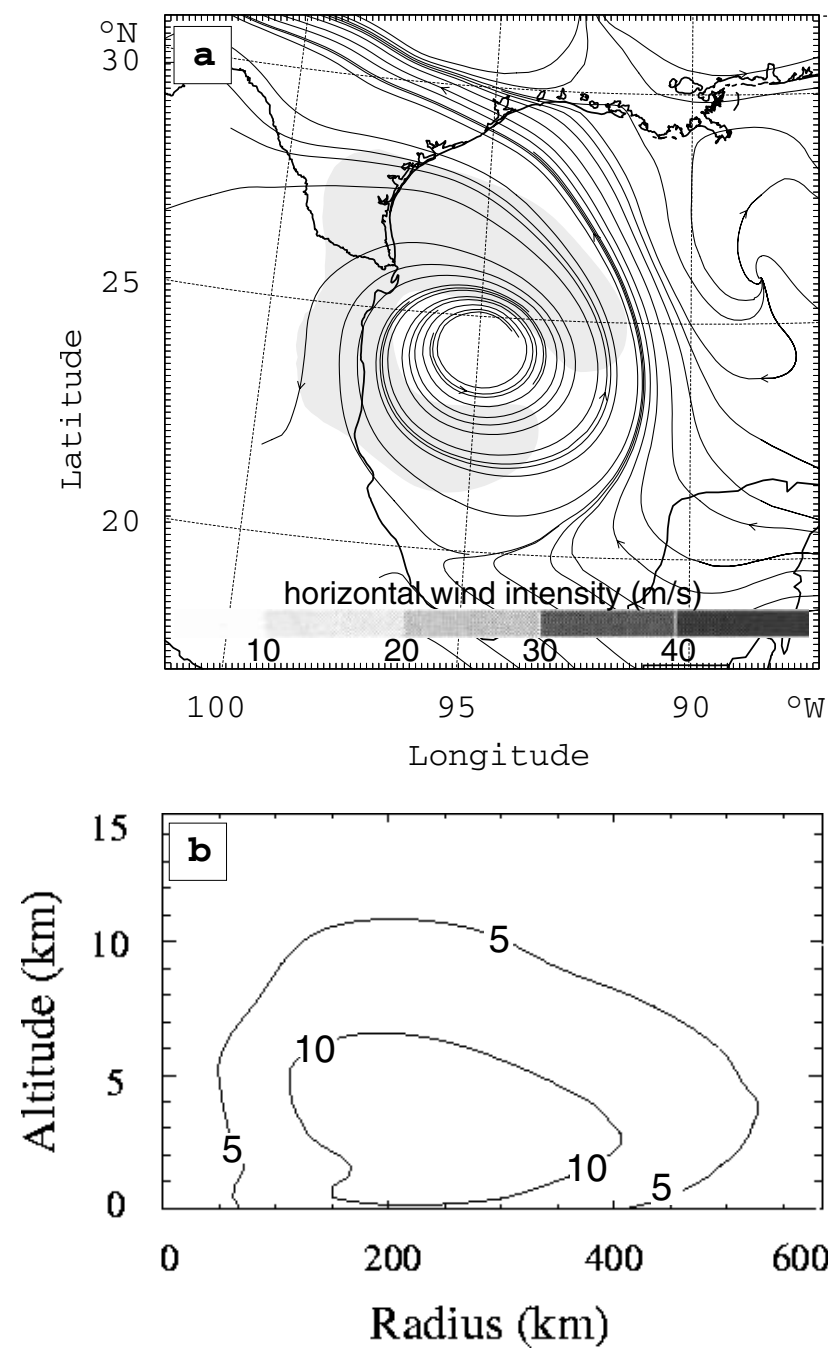

Figure 4. (a) Horizontal streamlines at $850 \mathrm{hPa}$ from the ECMWF global analysis at 0000 UTC 22 August; (b) radius-height distribution of tangential wind in the analysed vortex.

are certainly important in explaining the rapid deepening of the storm, from $979 \mathrm{hPa}$ at $1200 \mathrm{~h} 21$ August to $956 \mathrm{hPa}$ at $0000 \mathrm{~h} 22$ August, as it moved north and northwestward. The presence of stronger wind shear on the western periphery of the storm is probably related to the high terrain of Sierra Madre Oriental in Mexico. The largescale westerlies on the western periphery of the storm could have had some influence in keeping Bret over the Gulf of Mexico on 21 and 22 August. Moreover, upper-level divergence (not shown) reveals well-defined anticyclonic flow extending over Hurricane Bret, which was located at the western periphery of a mid- to upper-tropospheric ridge.

Although the large-scale analysis depicts favourable conditions for tropical cyclone intensification, the ECMWF model, because of its coarse horizontal resolution, failed to properly reproduce the mature hurricane. A preliminary step in improving the intialization of our simulation is to identify the vortex corresponding to Hurricane Bret in the analysed fields. Figure 4 displays the horizontal and vertical distribution of winds 
in the analysed vortex at $0000 \mathrm{~h} 22$ August. A low-level cyclonic circulation is found over the western Gulf of Mexico, but it does not have the correct scale nor intensity compared to the observed characteristics of Bret. The 'ECMWF storm' appears as a large, weak and shallow vortex with a radius of maximum wind (RMW) of about $200 \mathrm{~km}$ and maximum winds less than $12 \mathrm{~m} \mathrm{~s}^{-1}$. This is very different from the radar-derived values which show maximum winds of $48 \mathrm{~m} \mathrm{~s}^{-1}$ at $28-30 \mathrm{~km}$ radius (see below). The motion of such a shallow vortex is mostly controlled by low-level winds, while the actual hurricane which occupies a deeper layer was certainly influenced by environmental winds throughout the troposphere, so it is not surprising that significant differences are found between the track and evolution of the ECMWF storm and the one observed.

In addition to an ill-defined vortex structure and intensity, there is a significant dry bias in the analysed humidity field, especially in the mid-troposphere. Similarly, Liu et al. (1997) found that the National Centers for Environmental Prediction largescale analysis for Hurricane Andrew (21-24 August 1992) was too dry. Figure 5(b) shows the mean relative humidity between 700 and $400 \mathrm{hPa}$ from the ECMWF analysis, and Fig. 5(c) a modified analysis including the dropsonde observations. A variational interpolating and filtering technique, initially developed by Moine (2001) to analyse dropsonde data from FASTEX (Fronts and Atlantic Storm-Track Experiment), was used to retrieve the modified three-dimensional humidity fields from the series of dropsonde profiles in a sub-domain encompassing most of G-IV trajectory. In the ECMWF analysis (Fig. 5(b)), the mid-tropospheric environment around Hurricane Bret is particularly dry, with relative humidity less than $60 \%$ over a large part of Gulf of Mexico, which is unfavourable to the development of a strong hurricane. On the other hand, the dropsonde composite (Fig. 5(c)) displays significantly wetter conditions (relative humidity values of 60 to $80 \%$ ), especially in the northern part of the Gulf and south of Bret. Therefore, the ECMWF-analysed humidity field is replaced by that derived from the dropsonde observations in the domain shown in Fig. 5(b), which is slightly larger than domain B in Fig. 1.

\section{(b) Removal of the analysed vortex}

To incorporate a hurricane-like vortex with realistic size, depth, and intensity in the MésoNH initial conditions, it is first necessary to remove the weak vortex analysed by ECMWF. For this purpose, we applied the scheme proposed by Kurihara et al. (1993 hereafter KBR93, 1995); which consists of using appropriate numerical filters to extract the vortex from the large-scale analysis and adding a vortex specified from observations. This can be written symbolically as:

$$
\left[h_{\mathrm{i}}\right]=[h]-\left[h_{\mathrm{av}}\right]+\left[h_{\mathrm{s}}\right],
$$

where $\left[h_{\mathrm{i}}\right]$ is the initial field, $[h]$ is the global analysis, $\left[h_{\mathrm{av}}\right]$ is the analysed vortex and $\left[h_{\mathrm{s}}\right]$ is the specified vortex.

A low-pass filter with an exponential weighting function is first applied to the modified ECMWF field $[h]$ over domain A $(45 \mathrm{~km})$ to remove features with wavelengths smaller than about $1200 \mathrm{~km}$, the characteristic dimension of the analysed vortex. Using the same terminology as KBR93, this produces the basic field $\left[h_{\mathrm{b}}\right]$, which is subtracted from $[h]$ to obtain the total disturbance field $\left[h_{\mathrm{d}}\right]$ :

$$
[h]-\left[h_{\mathrm{b}}\right]=\left[h_{\mathrm{d}}\right]=\left[h_{\mathrm{av}}\right]+\left[h_{\mathrm{nh}}\right],
$$

where $\left[h_{\mathrm{nh}}\right]$ is the non-hurricane disturbance. 

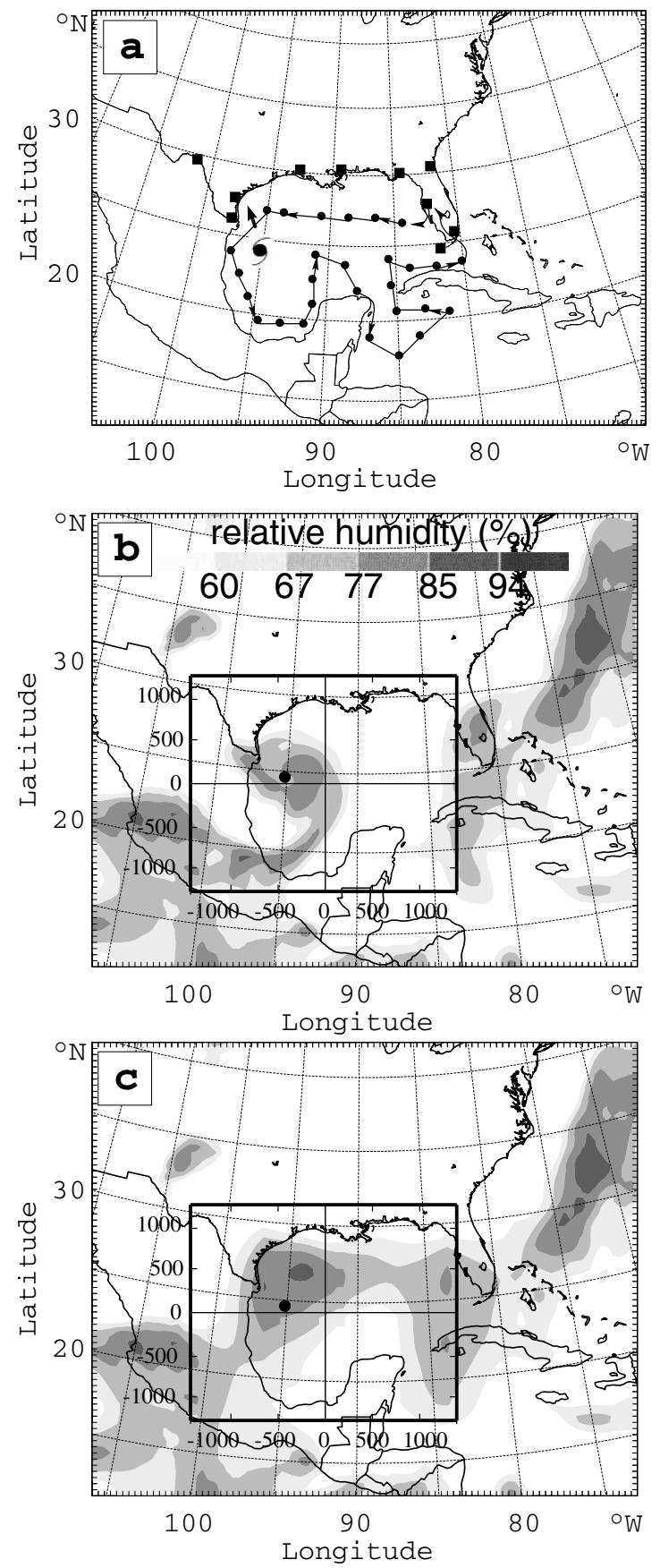

Figure 5. (a) Omega dropsonde sampling from the NOAA Gulfstream IV-SP aircraft from 1751 UTC 21 August to 0143 UTC 22 August (black dots) and location of radiosoundings available at 00 UTC 22 August near the Gulf of Mexico (black squares); (b) mid-tropospheric (700-400 hPa) relative humidity (\%), from the ECMWF global analysis at 0000 UTC 22 August; (c) mid-tropospheric relative-humidity field from a modified analysis including the data from OMEGA dropsondes. 
The next step consists of extracting $\left[h_{\mathrm{av}}\right]$ from $\left[h_{\mathrm{d}}\right]$. This is done using the same cylindrical filter as that proposed by KBR93:

$$
h_{\mathrm{av}}(r, \theta)=h_{\mathrm{d}}(r, \theta)-\left[h_{\mathrm{d}}\left(r_{0}, \theta\right) E(r)+\left\langle h_{\mathrm{d}}\left(r_{0}\right)\right\rangle\{1-E(r)\}\right],
$$

where $r$ and $\theta$ are the radius and the azimuth relative to the centre of the analysed vortex, $r_{0}$ is the radius at which the value of weighting function $E(r)=1$, and $\left\langle h_{\mathrm{d}}\left(r_{0}\right)\right\rangle$ is the mean value of $h_{\mathrm{d}}(r, \theta)$ for $r=r_{0}$ and $0 \leq \theta<2 \pi$. The function $E(r)$ (see Eq. (3.8) and Fig. 2(b) in KBR93) is an empirically determined exponential equation which increases smoothly from 0 at $r=0$ to 1 at $r=r_{0}$, with a smooth transition between the inner (i.e. hurricane component for $r<r_{0}$ ) and the outer regions (i.e. non-hurricane component for $\left.r>r_{0}\right)$.

For simplicity, and since Hurricane Bret was a relatively small and symmetric storm, we determine the radius $r_{0}$ of the filtering domain from the azimuthally averaged tangential wind $V_{\mathrm{T}}(r)$. The radius $r_{0}$ is defined as that beyond which the conditions $V_{\mathrm{T}}<$ $5 \mathrm{~m} \mathrm{~s}^{-1}$ and $\partial V_{\mathrm{T}} / \partial r<3 \times 10^{-6} \mathrm{~s}^{-1}$ or $V_{\mathrm{T}}(r)<2 \mathrm{~m} \mathrm{~s}^{-1}$ are met from the surface up to $300 \mathrm{hPa}$, which gives a value of $1025 \mathrm{~km}$. A visual inspection of individual dropsonde winds on 21 August (not shown) confirms that the cyclonic circulation associated with Hurricane Bret did not extend over a much larger region. The wind, temperature and pressure fields are filtered using this technique. The filtered environmental wind field is shown in Fig. 6(a).

\section{(c) A 'specified vortex' derived from airborne Doppler radar observations}

After the analysed vortex has been removed, the resulting environmental fields are used as new large-scale conditions, and interpolated over the MésoNH model domains A, B, C and D (see Fig. 1). A symmetrical radar-derived vortex deduced from airborne Doppler radar observations is then added to this modified large-scale field in domains A, B, C and D (Fig. 6(b)). This method is referred to as the "radar dropsonde vortex conditioning' (RDVC).

The wave number-zero component of the tangential wind, deduced from the Extended Velocity-Track Display (EVTD) analysis (Roux and Marks 1996) of the airborne Doppler data collected from 2005 to $2310 \mathrm{~h}$, is shown in Fig. 7(a). The wind intensity reaches a maximum of $48 \mathrm{~m} \mathrm{~s}^{-1}$ at $25 \mathrm{~km}$ radius below $1 \mathrm{~km}$ altitude, and it decreases with radius and altitude: to $30 \mathrm{~m} \mathrm{~s}^{-1}$ at $30 \mathrm{~km}$ radius and $10 \mathrm{~km}$ altitude, and to $25 \mathrm{~m} \mathrm{~s}^{-1}$ at $85 \mathrm{~km}$ radius and $1 \mathrm{~km}$ altitude. Although these EVTD-derived velocities bring valuable information on the storm dynamic structure, they do not cover a large enough domain to properly define the specified vortex. Hence, we used an analytic model to describe the radial and vertical distribution of the tangential wind over a larger domain. The analytic wind $V_{\mathrm{T}}^{*}(r, z)$, where $z$ is altitude, is defined through a simplified version of the formulation proposed by Holland (1980), as:

$$
V_{\mathrm{T}}^{*}(r, z)=V_{\mathrm{T} \max }(z)\left\langle\frac{\exp \left\{1-1 /[r / R M W(z)]^{B(z)}\right\}}{[r / R M W(z)]^{B(z)}}\right\rangle^{1 / 2},
$$

where $V_{\mathrm{T} \max }(z)$ is the maximum wind, $R M W(z)$ is the radius of maximum wind, and $B(z)$ is a scaling parameter for the radial variation of the wind. In order to avoid spurious variations of $V_{\mathrm{T} \max }, R M W$ and $B$ between the different levels, we suppose that they obey 

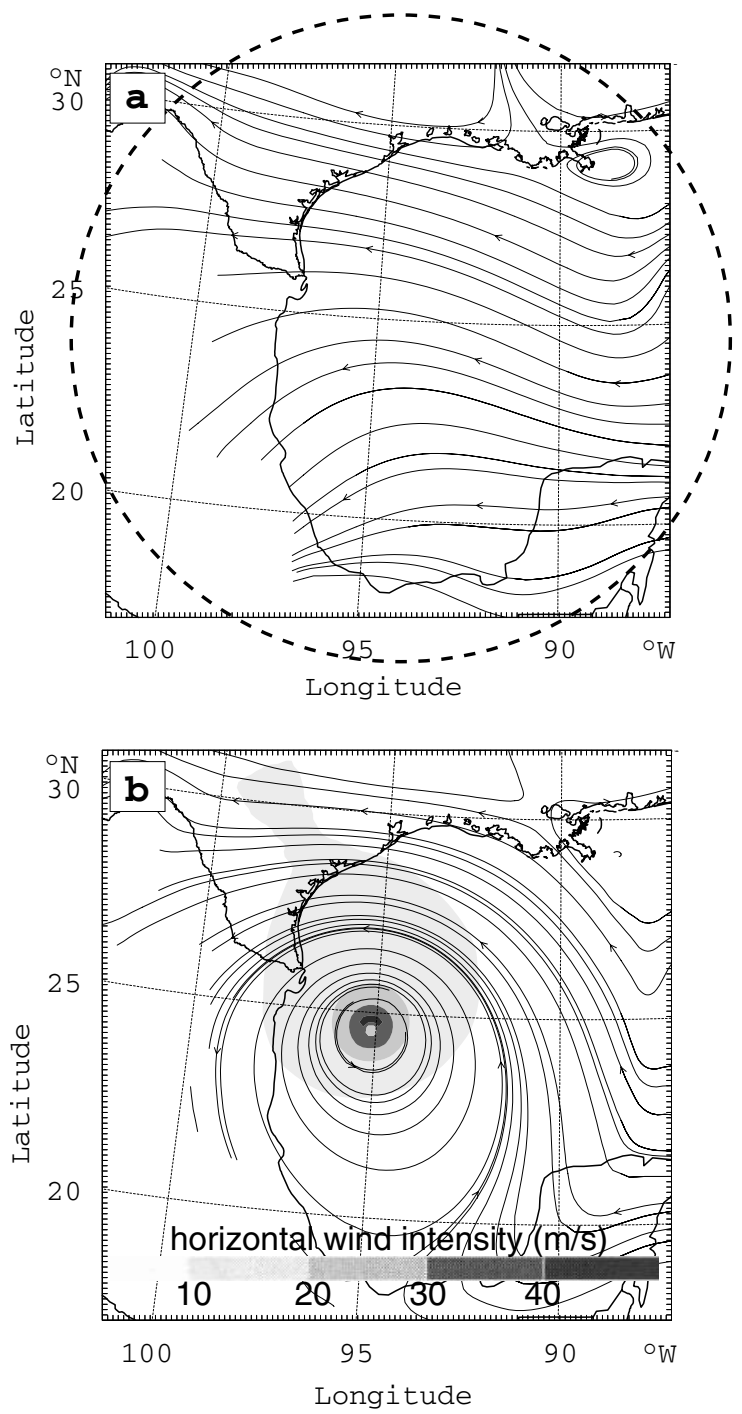

Figure 6. (a) As Fig. 4(a), except for the filtered analysis, referred to as GLOBAL ANALYSIS, the dashed circle denotes radius $r_{0}$ which separates the HURRICANE and NON-HURRICANE components; (b) as in (a), except for the inclusion of the airborne Doppler radar-derived SPECIFIED VORTEX. See text for details.

the following relations with respect to $z$ :

$$
\begin{gathered}
V_{\mathrm{T} \max }(z)=V_{\mathrm{T} \text { max } \_0}\left(\frac{1-z}{17.5 \mathrm{~km}}\right)^{C}, \\
R M W(z)=R M W_{0}+R M W_{z} \times z+R M W_{z z} \times z^{2}, \\
B(z)=B_{0}+B_{z} \times z+B_{z z} \times z^{2},
\end{gathered}
$$

where $B_{0}, B_{z}, B_{z z}$ are constants. Once $V_{\mathrm{T} \max }(z)$ and $R M W(z)$ have been determined at each level from the EVTD-derived tangential winds, coefficients $V_{\mathrm{T} \text { max_0 }}$ and $C$ in (5), $R M W_{0}, R M W_{z}$ and $R M W_{z z}$ in (6) are deduced from least-squares fits along the vertical. Then, parameters $B_{0}, B_{z}$ and $B_{z z}$ in (7) are deduced from a least-squares fit of the 

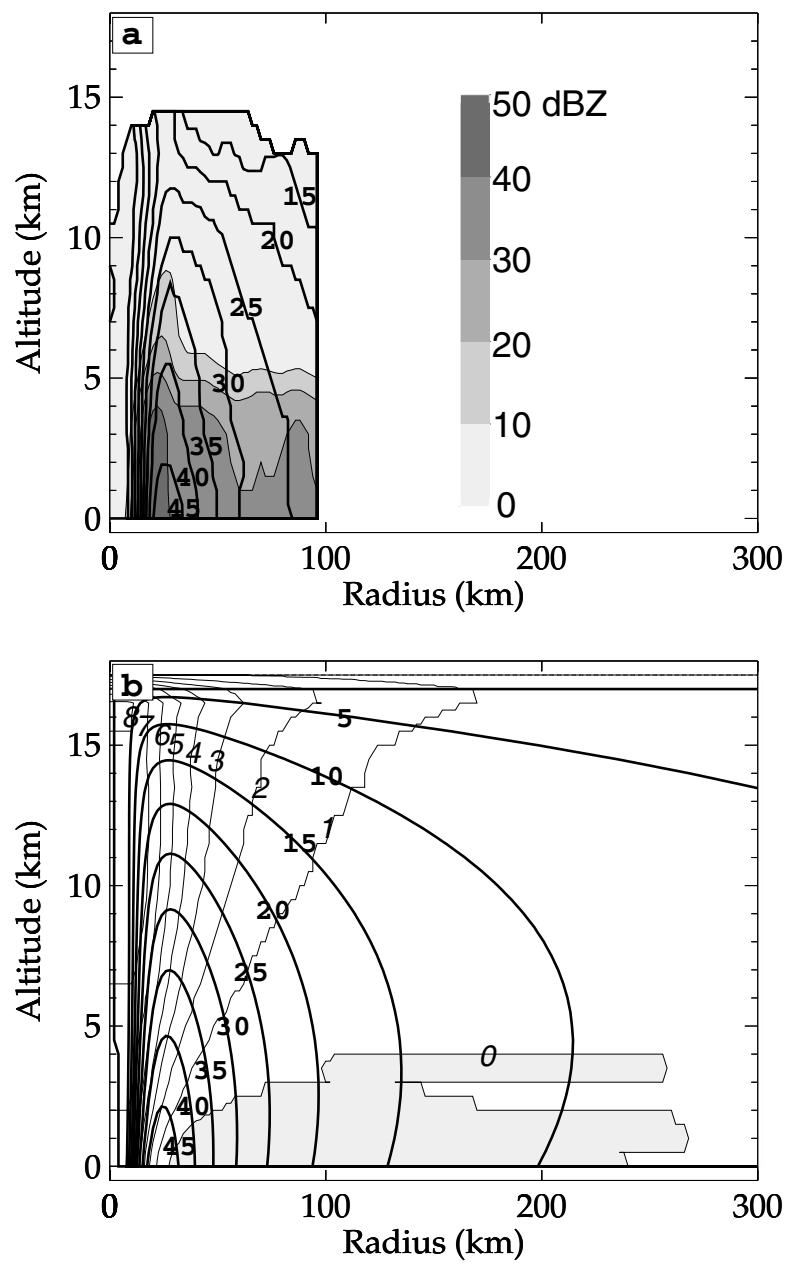

Figure 7. Radius-height distribution of: (a) radar reflectivity (grey scale, contours every 10 dBZ) and EVTDderived (see text) tangential velocity (thick lines, contours every $5 \mathrm{~m} \mathrm{~s}^{-1}$ ) from the airborne Doppler data in Hurricane Bret (2005-2305 UTC 21 August); (b) analytical tangential velocity (thick lines, contours every $5 \mathrm{~m} \mathrm{~s}^{-1}$ ) and potential-temperature perturbation (thin lines, contours every $1 \mathrm{~K}$ ) from thermal-wind balance; (c) analytical radial velocity (contours every $2 \mathrm{~m} \mathrm{~s}^{-1}$, shaded zones denote negative values or inflow); (d) analytical vertical velocity (contours every $0.5 \mathrm{~m} \mathrm{~s}^{-1}$ ).

EVTD-derived winds in the radius-height domain, with the constraint that $B(z)$ must be between 1.0 and 2.5 (Holland 1980). The obtained rms values of the EVTD-derived tangential wind, those derived from (4), and their rms difference are 24.9, 27.4 and $4.3 \mathrm{~m} \mathrm{~s}^{-1}$, respectively, which indicates that this analysis induces only minor changes in the wind field. As seen in Fig. 7(b), although smoother, the analytic winds are very similar to the EVTD-derived ones at radii $<100 \mathrm{~km}$ and altitudes $<15 \mathrm{~km}$, and are realistic beyond these limits.

As shown by $\mathrm{Pu}$ and Braun (2001), a numerical model may produce more realistic tropical cyclones when a specified vortex includes wind and sea-level pressure information. Pressure perturbations associated with a tropical cyclone are mainly caused by hydrostatic effects due to the warm anomaly at its centre. Hence, the specified vortex to be added to the large-scale analysis must include complementary descriptions of the 

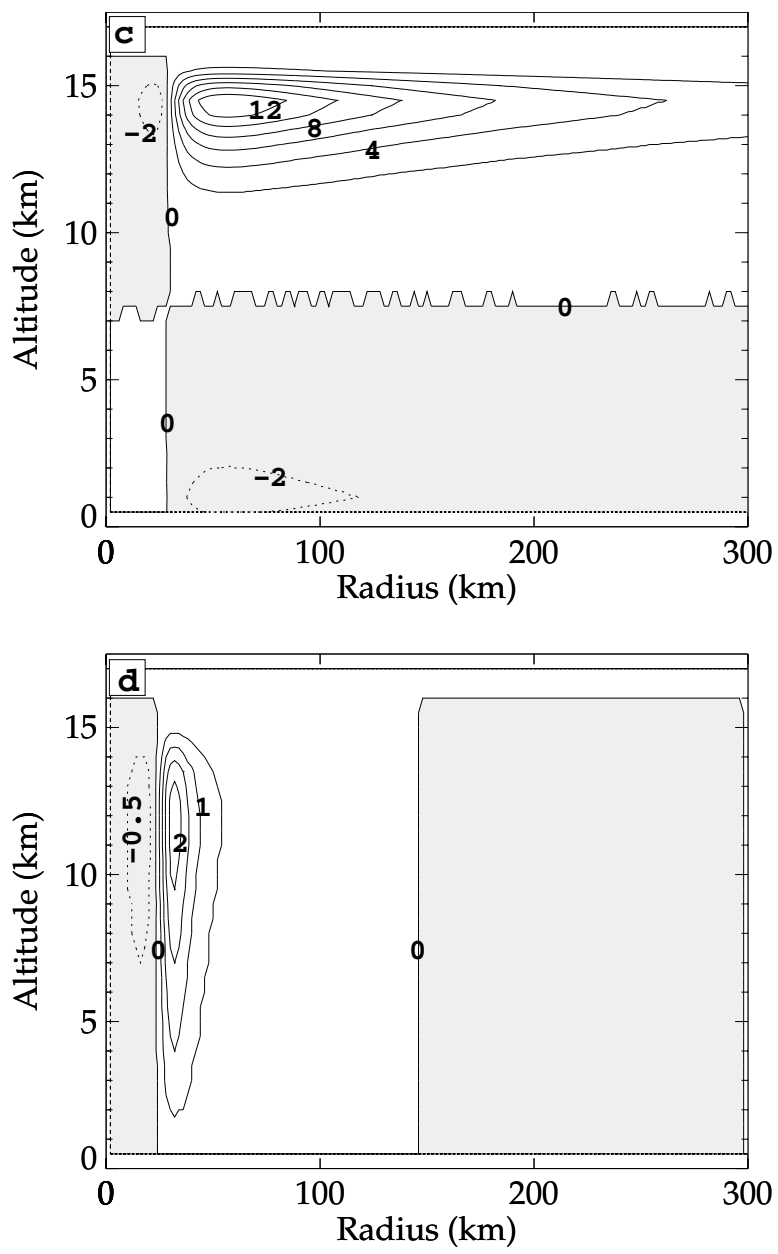

Figure 7. Continued.

cyclonic wind and temperature perturbations. Temperature can be deduced from the analytic tangential wind $V_{\mathrm{T}}^{*}(r, z)$ in (4) through the thermal-wind relation:

$$
\frac{\partial}{\partial r} \theta_{1}(r, z)=\frac{\theta_{0}(z)}{g}\left\{2 \frac{V_{\mathrm{T}}^{*}(r, Z)}{r}+f\right\} \frac{\partial}{\partial \zeta} V_{\mathrm{T}}^{*}(r, Z),
$$

where $\theta_{0}(z)$ is the potential temperature in the environment $\left(\left[h_{\mathrm{b}}\right]\right.$ in $\left.(2)\right), \theta_{1}(r, z)$ is the cyclonic perturbation, $f$ is the Coriolis parameter, $g$ is the acceleration due to gravity, $Z$ is a modified vertical coordinate such that $Z=z \times\left\langle\theta_{0}\right\rangle / \theta_{0}(z)$, where $\left\langle\theta_{0}\right\rangle$ is the mean value of $\theta_{0}(z) . \theta_{1}(r, z)$ is obtained from the horizontal integration of (7) starting from 0 at $300 \mathrm{~km}$ radius. Of course, due to the exponential decrease of the analytic tangential wind in (3), it is not strictly correct to suppose that temperature perturbations vanish at $300 \mathrm{~km}$ radius. However, the relatively weak value and radial gradient of $V_{\mathrm{T}}^{*}(r, z)$ beyond this limit make the difference quite negligible. The deduced potential-temperature perturbations (Fig. 7(b)) display a realistic warm core structure with maximum values at the centre of the specified vortex, from $5.6 \mathrm{~K}$ at the surface to $8.1 \mathrm{~K}$ at $16 \mathrm{~km}$ altitude. 
It is important to note that the specified vortex is symmetric, and does not contain asymmetric flow such as ' $\beta$ circulations' or ' $\beta$ gyres'. Previous numerical studies (e.g. DeMaria 1985; Fiorino and Elsberry 1989; Shapiro and Ooyama 1990; Smith et al. 1990) have shown that these gyres can have a substantial effect on the propagation of tropical cyclones, with a more pronounced poleward and westward motion even in the absence of steering environmental flow. Here, we rely on MésoNH to progressively recreate these features through interactions between the specified vortex, the environmental wind and the planetary vorticity. It must, however, be mentioned that adding the specified vortex to the predominantly easterly flow creates an asymmetry, with slightly stronger winds in the northern part of the storm (Fig. 6(b)). To take into account the observed asymmetric structure of the inner core (i.e. wave numbers one and two in the EVTD analysis; Roux and Marks (1996)) in the determination of the specified vortex, it would be necessary to consider a three-dimensional balance formulation such as the 'asymmetric balance' (Shapiro and Montgomery 1993).

We have also tested the impact of adding a secondary (radial and vertical) circulation. Specification of an initial symmetric secondary circulation is possible through an analytical radial-vertical mass-flux stream function, $\Psi$, (not shown) which ensures that the radial wind, $V_{\mathrm{R}}$, and vertical wind, $W$, obey the continuity equation, through:

$$
V_{\mathrm{R}}=-\frac{1}{2 \pi \rho r} \frac{\partial \Psi}{\partial z} \quad \text { and } \quad W=+\frac{1}{2 \pi \rho r} \frac{\partial \Psi}{\partial r}
$$

where $\rho$ is the air density at the considered altitude. Based on previous analyses of hurricane inner-core winds (e.g. Roux and Viltard 1995) the analytical secondary circulation (Figs. 7(c) and (d)) is characterized by a $25 \mathrm{~km}$ wide updraught centred on the radius of maximum wind, with a maximum of $2.5 \mathrm{~m} \mathrm{~s}^{-1}$ at $11.5 \mathrm{~km}$ altitude. Consequently, there is a weak inflow below $7 \mathrm{~km}$ altitude, with radial winds $<-2 \mathrm{~m} \mathrm{~s}^{-1}$ below $2 \mathrm{~km}$ altitude, and a stronger outflow (due to the much reduced air density aloft) between 11.5 and $15.5 \mathrm{~km}$ altitude which decreases at larger radii. A weak downdraught $\left(\leq-0.5 \mathrm{~m} \mathrm{~s}^{-1}\right)$ at radii $<25 \mathrm{~km}$, in the outer part of the eye, is associated with weak inflow aloft and outflow at low levels. Although such a radial and vertical circulation is relatively realistic, it must be emphasized that it certainly lacks physical consistency. Indeed, to correctly specify an initial symmetric secondary circulation it would be necessary that $\Psi$ obeys a diagnostic second-order differential equation, with source and sink terms related to unknown momentum and heat fluxes at the surface and aloft (Shapiro and Willoughby 1982). In the model (as in reality) the radial and vertical circulation results from: sensible- and latent-heat fluxes from the ocean surface increasing $\theta_{\mathrm{E}}$ in the lowest atmospheric layers; surface friction inducing radial convergence; latent-heat release sustaining vertical motions through thermal buoyancy; and vertical momentum fluxes generating horizontal and vertical pressure perturbation gradients. Including these physical constraints in an analytical formulation would be a very difficult task. Nevertheless, some tests discussed below were made to check the impact of taking into account a secondary circulation in the specified vortex.

\section{(d) Numerical experiments}

We performed a series of four different $30 \mathrm{~h}$ simulations of Hurricane Bret from 0000 h 22 August to 0600 h 23 August:

(i) CTL is a control experiment with the unmodified ECWMF analysis, and only domains $\mathrm{A}(45 \mathrm{~km})$ and $\mathrm{B}(15 \mathrm{~km})$;

(ii) Low RDVC is an experiment with the specified vortex, and domains A and B only; 


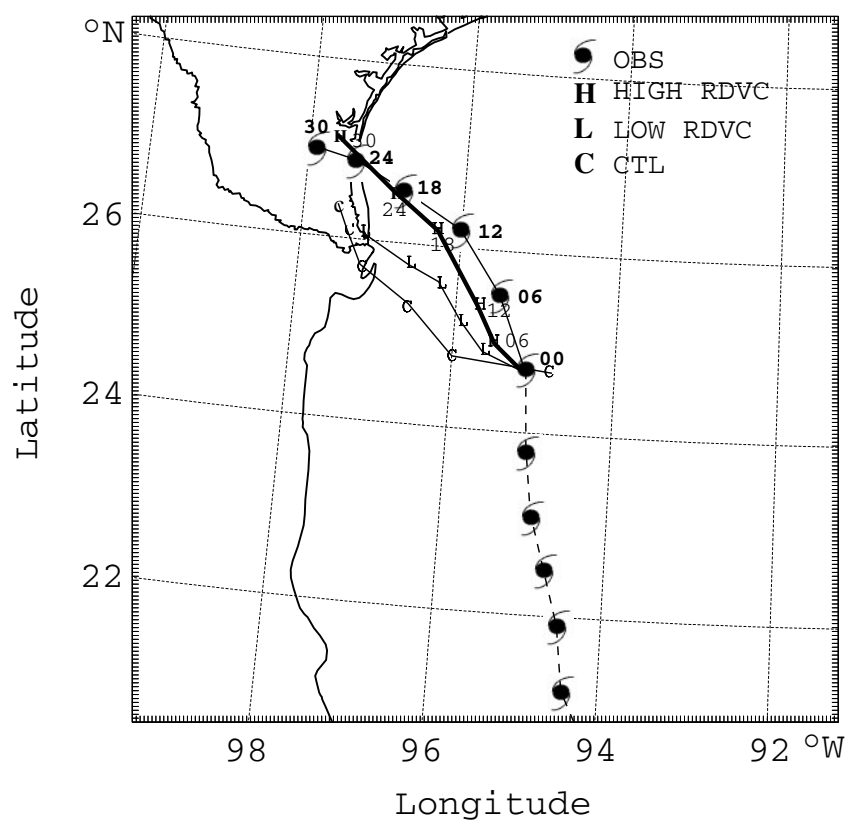

Figure 8. Best analysed trajectory of Hurricane Bret (OBS) every 6 h starting at 1800 UTC 20 August) and of the simulated storm for experiments CTL (C), Low-RDVC (L) and High-RDVC (H) from 0000 UTC 22 August to 0600 UTC 23 August. See text for further details.

(iii) High RDVC is similar to Low RDVC, but with the four domains A, B, C (5 km) and $\mathrm{D}(1.67 \mathrm{~km})$;

(iv) High RDVC/SC is similar to High RDVC but with an analytical secondary circulation included in the specified vortex.

Low RDVC and High RDVC were conducted to evaluate the dependence of simulated track and intensity on the horizontal resolution and accuracy of the specified vortex.

\section{Structure AND EVOlution OF THE Simulated STORM}

\section{(a) General characteristics of the numerical experiments}

Figure 8 shows the tracks of Hurricane Bret obtained for CTL, Low-RDVC and High-RDVC experiments starting at 0000 h 22 August, compared to the best track analysis.

In the CTL experiment, the simulated storm propagates rapidly westward during the first $6 \mathrm{~h}$ before turning north-westward and moving at a slightly slower speed, which leads to landfall at $1800 \mathrm{~h} 22$ August over the Mexican coast, about $140 \mathrm{~km}$ south of the observed location and $6 \mathrm{~h}$ earlier.

Although in the Low-RDVC experiment landfall error is still large (about $100 \mathrm{~km}$ too far south) it improves the simulated hurricane track, with a more realistic northwestward trajectory from 0600 to $1800 \mathrm{~h} 22$ August, followed by a westward deviation. However, the storm motion is too slow and landfall occurs at $0600 \mathrm{~h} 23$ August, $6 \mathrm{~h}$ later than the observed time. 
The trajectory of the tropical cyclone in the High-RDVC experiment is closer to reality. Although the direction of vortex motion is too far west during the first $6 \mathrm{~h}$, and its speed is too slow during the first $12 \mathrm{~h}$, the track is then nearly parallel to that observed, and the simulated landfall occurs about $20 \mathrm{~km}$ north of the observed location at $0330 \mathrm{~h}$ 22 August.

Since the vertical structure of the initial vortex is poorly defined in the CTL experiment, interactions between the tropical cyclone and its environment are not correctly reproduced which has an impact on the propagation of the simulated storm. The fact that better results are obtained from the Low-RDVC experiment is consistent with the results obtained by Xiao et al. (2000) for numerical simulations of Hurricane Fran (1996). They found that hurricanes with a large radius of maximum sea-levelpressure gradient are prone to a more westward and faster propagation, possibly due to higher sensitivity to lower-tropospheric conditions. By comparing the results from Low-RDVC and High-RDVC experiments, we can also appreciate the sensitivity of the model to horizontal-grid resolution. With a $1.67 \mathrm{~km}$ resolution (domain $\mathrm{D}$ ), the model is able to explicitly and more correctly simulate deep moist convection in the eyewall region, which plays a role in storm intensity and propagation.

Figure 9 shows the evolution of the maximum azimuthally averaged tangential wind at $1 \mathrm{~km}$ altitude (Fig. 9(a)) and of the minimum sea-level pressure (Fig. 9(b)) for the CTL, Low-RDVC and High-RDVC experiments. The observed values are also shown for comparison. With a larger and weaker initial vortex from the large-scale analysis, the CTL experiment shows a slow intensification during the whole period, reaching only $20 \mathrm{~m} \mathrm{~s}^{-1}$ and $994 \mathrm{hPa}$ at the end of the simulation time; both values are far less intense than those observed. It can be noted that, probably due to this relatively weak intensity, wind speed and surface pressure in the CTL experiment do not show significant change at landfall (1800 h 22 August), as is usually observed.

Compared to CTL, differences with observations are significantly smaller for the Low-RDVC and High-RDVC experiments. The initial vortex-adjustment period (defined as the time necessary for the simulated storm to reach an intensity equal to the initial one after an initial weakening phase) lasts about $6 \mathrm{~h}$ in both cases. However, major differences appear during storm evolution, and results from High-RDVC are in better agreement with the observations, especially during the second half of the simulation (after $12 \mathrm{~h}$ of simulated time). For this experiment, the model strengthens the initial storm to category-four intensity with a maximum azimuthal mean wind of about $66 \mathrm{~m} \mathrm{~s}^{-1}$ at $1 \mathrm{~km}$ altitude and a minimum central pressure of $946 \mathrm{hPa}$ at 1800 h 22 August. Afterwards, the High-RDVC results correctly reproduce the observed weakening until the end of the simulation time. Considering that there is a $3 \frac{1}{2} \mathrm{~h}$ delay between actual and simulated landfall, it is not surprising that the simulated storm weakened less rapidly than the observed one after $1800 \mathrm{~h}$.

It can also be seen in Fig. 9 that adding an analytical secondary circulation in the specified vortex (experiment High RDVC/SC) does not significantly change the evolution of the simulated storm during the first $12 \mathrm{~h}$, with a very small increase of the maximum wind and decrease of the minimum surface pressure compared to the High-RDVC results. Whereas the tangential wind and the temperature perturbations of the primary circulation are in thermal-wind balance, and can therefore be maintained for several hours without substantial attenuation except for turbulent diffusion, the analytical secondary circulation does not initially fit in with the simulated surface and convective heat and momentum fluxes, and cannot persist for long before being progressively replaced by radial and vertical winds more coherent with the simulated physics. 

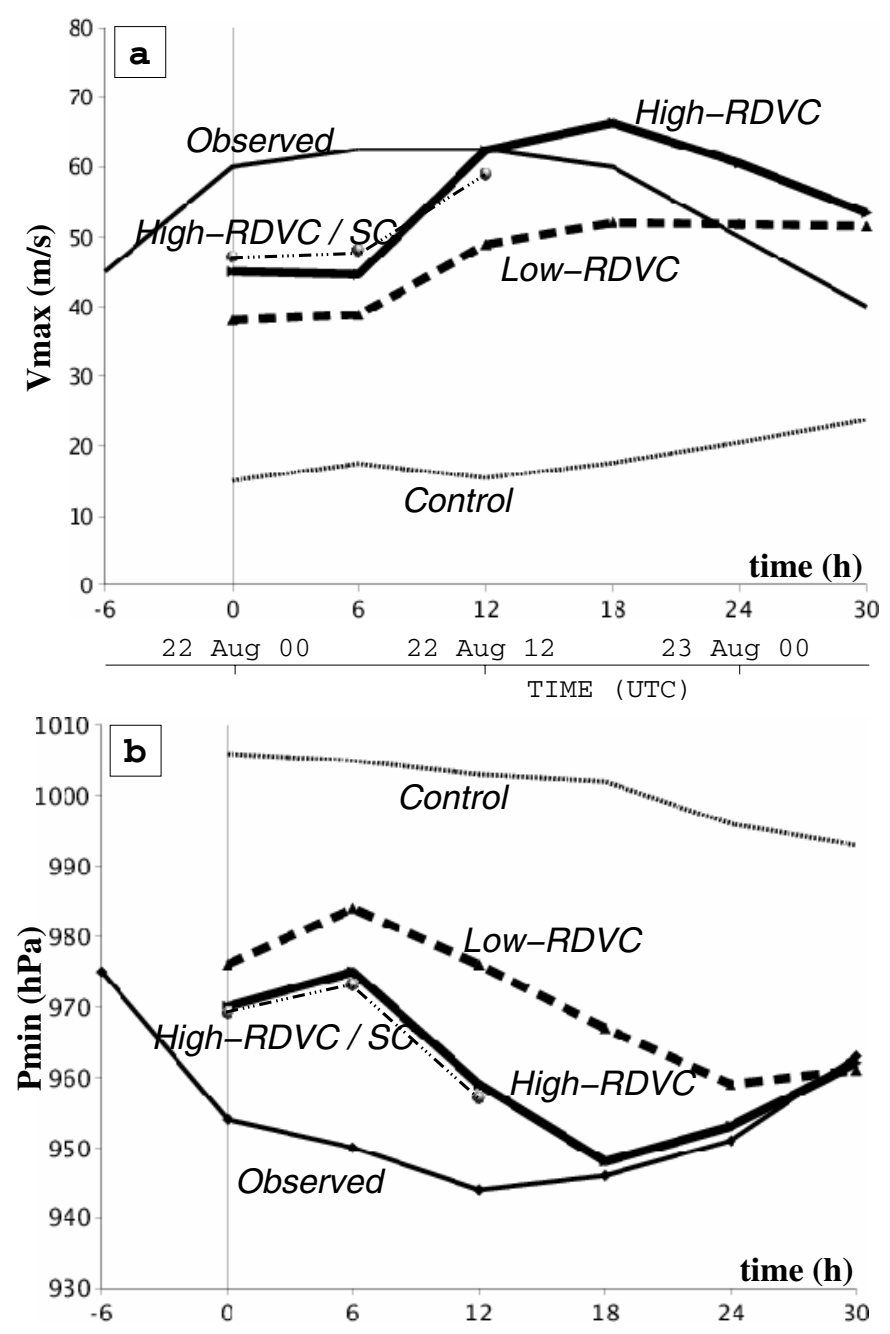

Figure 9. (a) Evolution of the maximum sustained wind speed (Observed), and of the maximum azimuthally averaged tangential wind at $1 \mathrm{~km}$ altitude for experiments CTL, Low-RDVC, High-RDVC and High-RDVC/SC; (b) as in (a) but for the minimum sea-level pressure. See text for details.

(b) Symmetric structure in the inner core at mature stage

In the following, we discuss only results from the High-RDVC experiment, which explicitly resolves the largest convective eddies and gives the most realistic simulations of Hurricane Bret's track and structure. The results are shown in a frame of reference moving with the storm, i.e. the storm motion components are subtracted before tangential and radial velocities are calculated. Figure 10 displays the axisymmetric (azimuthal mean) structure of the simulated storm at $1800 \mathrm{~h} 22$ August, when the simulated storm had reached a mature stage over the ocean (Fig. 9). Figure 10(a) shows the mean tangential wind, with a maximum of $63 \mathrm{~m} \mathrm{~s}^{-1}$ at about $20 \mathrm{~km}$ from the vortex centre and 500 $\mathrm{m}$ above sea level. The RMW increases with height, up to $40 \mathrm{~km}$ at $12 \mathrm{~km}$ altitude where the maximum wind is $25 \mathrm{~m} \mathrm{~s}^{-1}$. Near the ocean surface, the tangential wind is not as strong as above, with a maximum value $<55 \mathrm{~m} \mathrm{~s}^{-1}$ at RMW, because of momentum loss by friction. At radii larger than $50 \mathrm{~km}$ from the storm centre the wind intensity increases 

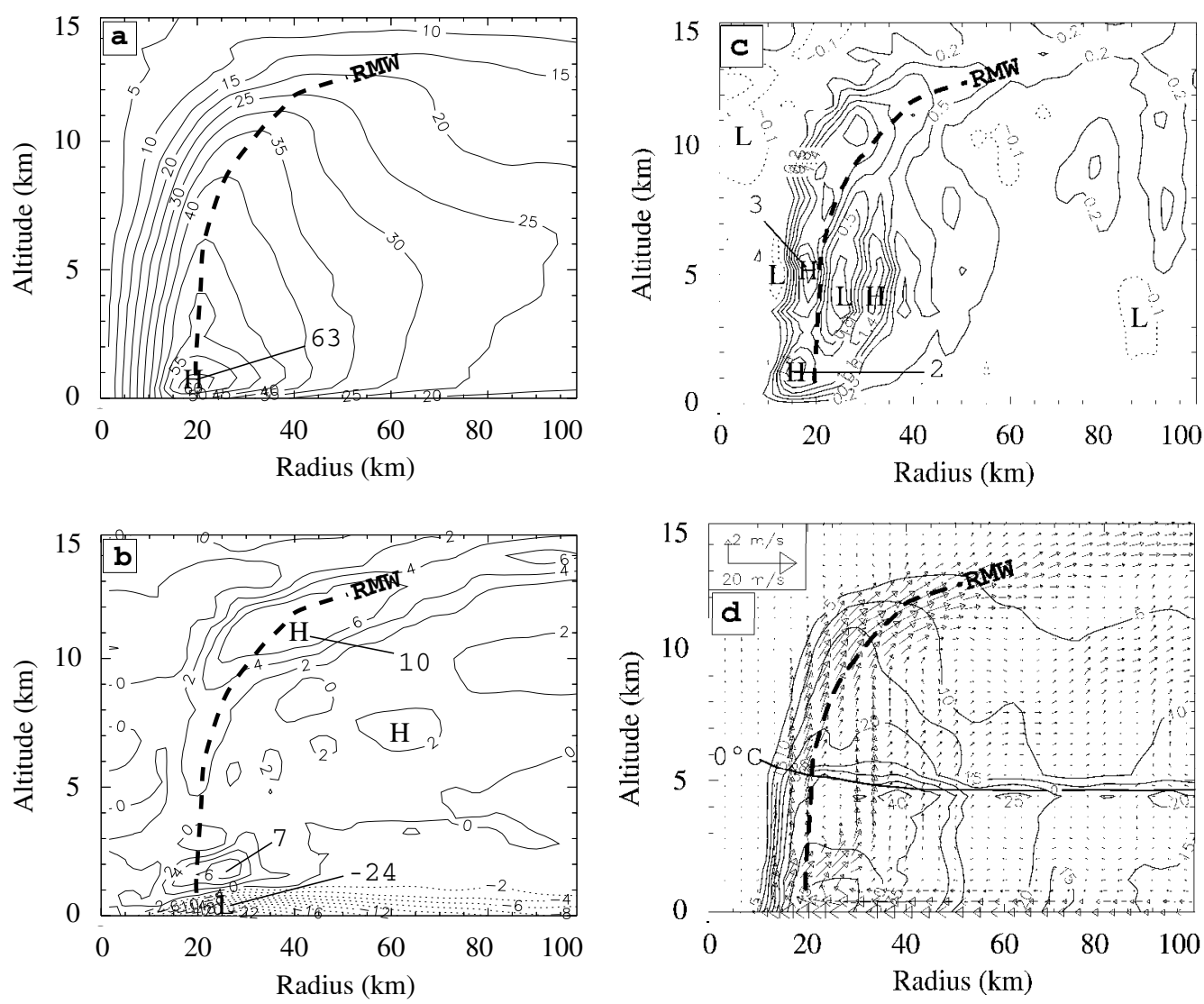

Figure 10. For the High-RDVC experiment, radius-height cross-sections of the azimuthally averaged fields of: (a) tangential wind (contours every $5 \mathrm{~m} \mathrm{~s}^{-1}$ ); (b) radial wind (contours every $2 \mathrm{~m} \mathrm{~s}^{-1}$, dashed lines denote negative values or inflow); (c) vertical velocity (contours every $0.3 \mathrm{~m} \mathrm{~s}^{-1}$, dashed lines denote negative values); (d) radial and vertical wind (arrows, scale in the upper left) and simulated radar reflectivity (contours every $5 \mathrm{dBZ}$ ), the thick solid line denotes the location of the $0^{\circ} \mathrm{C}$ isotherm; (e) perturbations with respect to the mean vertical profile of potential temperature at $100 \mathrm{~km}$ radius (contours every $1 \mathrm{~K}$ ); (f) equivalent potential temperature (contours every $2 \mathrm{~K}$ ). Simulation time is 1800 UTC 22 August, the thick-dashed line shows the position of the radius of maximum wind (RMW) at various levels. See text for further details.

with height, even above the top of the marine boundary layer where friction occurs, up to a progressively higher altitude $(2 \mathrm{~km}$ at $50 \mathrm{~km}$ radius, $5 \mathrm{~km}$ at $75 \mathrm{~km}$, and $6.5 \mathrm{~km}$ at $100 \mathrm{~km}$ ). Thermal-wind balance in a warm-core vortex cannot explain this kinematic structure which, as will be shown below, results from the thermodynamic characteristics of the radial inflow.

The mean radial wind (Fig. 10(b)) shows a very strong inflow (up to $-24 \mathrm{~m} \mathrm{~s}^{-1}$ ) in the lowest hundreds of metres at the RMW and beyond. The depth of the inflow region increases almost steadily from $1 \mathrm{~km}$ at $20 \mathrm{~km}$ radius to $6 \mathrm{~km}$ at $100 \mathrm{~km}$, but most of the inflow occurs within a hundred metres above the sea surface. Above $1 \mathrm{~km}$ altitude, the radial flow in the eyewall is mostly divergent, with an outflow channel $>4 \mathrm{~m} \mathrm{~s}^{-1}$ above $9 \mathrm{~km}$ altitude. Between 1 and $2 \mathrm{~km}$ altitude, just above the location of strongest low-level inflow, a relatively strong outflow (up to $+7 \mathrm{~m} \mathrm{~s}^{-1}$ ) injects air from the lower part of the eye into the eyewall. Such a low-level outward airstream was also observed by Liu et al. (1999) and Braun (2002) in their numerical simulations of Hurricanes Andrew (1992) and Bob (1991), respectively. They suggested that it could result from an overshoot 

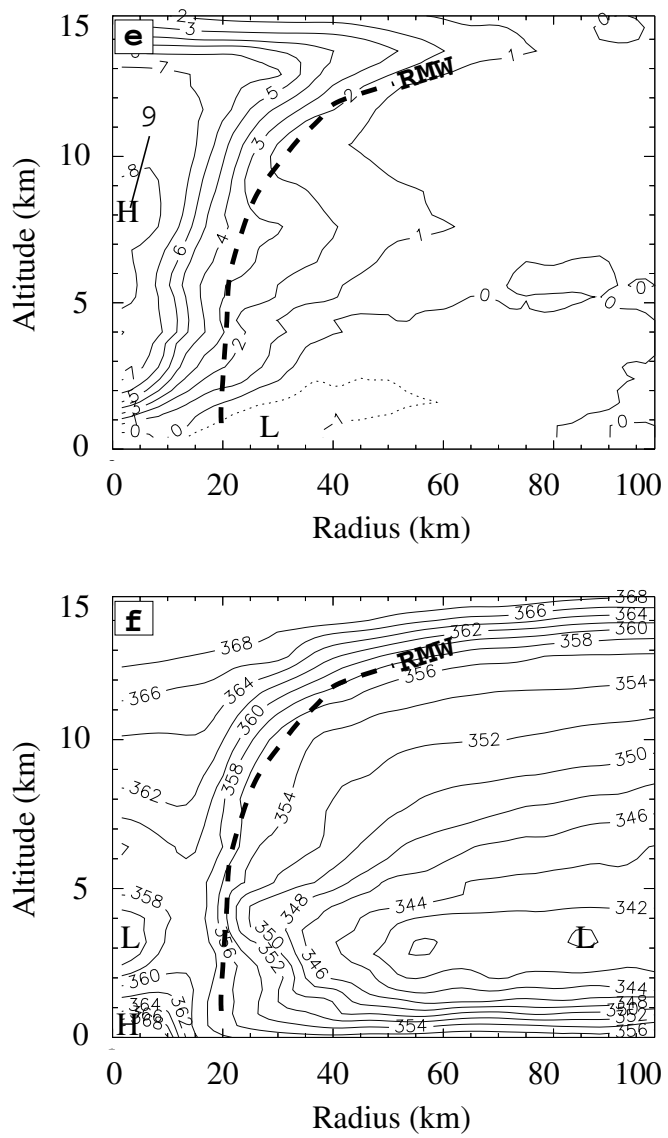

Figure 10. Continued.

effect applied to air parcels accelerated inward by the radial pressure gradient beyond their radius of equilibrium, and that it could play a role in reducing central pressure by drawing air out of the eye and in feeding eyewall convection with high- $\theta_{\mathrm{E}}$ air. In the eye (radius $<15$ to $20 \mathrm{~km}$ ) the weak radial flow is mostly inward $\left(V_{R}<0\right)$, with some contribution from the inner part of the eyewall above $9 \mathrm{~km}$ altitude.

The mean vertical velocity (Fig. 10(c)) shows strong slantwise ascent in the eyewall on the inner side of the RMW, with two maxima of about 2 and $3 \mathrm{~m} \mathrm{~s}^{-1}$ at 1 and $5 \mathrm{~km}$ altitude, respectively. The lowest corresponds to the upward acceleration of air parcels flowing horizontally from the eye toward the eyewall (Fig. 10(b)). It is, however, difficult to determine whether this is truly air of eye origin, or outside air that has penetrated to the inner part of the eyewall and is then moving back outward. At $5 \mathrm{~km}$ altitude, the presence of a minimum $\left(<0.2 \mathrm{~m} \mathrm{~s}^{-1}\right)$ between two peak updraughts at 19 and $33 \mathrm{~km}$ radii could result from reduced buoyancy due to condensed water loading in this region of relatively high equivalent reflectivity value, calculated from the simulated hydrometeor contents, implicit particle density and size distribution (Richard et al. 2003; Fig. 10(d)). Weak downward motion $\left(<-0.1 \mathrm{~m} \mathrm{~s}^{-1}\right)$ is found at radii $<15 \mathrm{~km}$ in the eye region above $8 \mathrm{~km}$ altitude, and along the inner side of the eyewall updraught, where reflectivity is very weak. At larger distances $(80-100 \mathrm{~km})$ from the storm centre, where precipitation is more stratiform (Fig. 10(d)), weaker mesoscale updraughts and downdraughts are 
observed above and below the level of the $0{ }^{\circ} \mathrm{C}$ isotherm. The sharp increase of the simulated reflectivity values just below the $0{ }^{\circ} \mathrm{C}$ isotherm is due to the melting of ice hydrometeors, with a higher dielectric constant.

The mean potential-temperature perturbation field (Fig. 10(e)) is defined, for each level, as the deviation from the averaged value at a radius of $100 \mathrm{~km}$ from the storm centre. The simulated tropical cyclone exhibited a warm-core structure with a maximum central anomaly of $+9 \mathrm{~K}$ at $8 \mathrm{~km}$ altitude, which indicates that downward motions at the storm centre resulted from thermally indirect subsidence (Willoughby 1998). This value and the altitude at which it occurred are in the lower range of those obtained in the numerical simulations of Liu et al. (1999), Wang (2001) and Braun (2002), but they are similar to the results retrieved from airborne Doppler radar data by Viltard and Roux (1998). These differences can result from different reference states (i.e. domainaveraged values versus far-environmental profile) leading to different amplitudes and vertical profiles of temperature anomaly. The negative temperature perturbations in the low levels, probably result from cooling due to melting of graupel and snow, and to evaporation of rain in the radial inflow. Following (8), the thermal-wind equation, the resulting positive radial gradient of temperature perturbation explains the positive vertical shear of tangential wind (Fig. 10(a)). It is also possible that radial and vertical momentum transport associated with the peak tangential winds rising with radius outward, lead to a tangential-wind pattern that subsequently induces a cold anomaly (with respect to the reference profile) through thermal-wind balance. In the eye, as found by Liu et al. (1999), the strong temperature inversion between 2 and $4 \mathrm{~km}$ altitude efficiently blocks vertical motions.

Figure 10(f) shows the equivalent potential temperature, $\theta_{\mathrm{E}}$ (where $\theta_{\mathrm{E}}=\theta \exp (L q /$ $\left.C_{P} T\right)$, where $L$ is the latent heat of vaporization, $q$ is specific humidity and $C_{P}$ is the specific heat at constant pressure). This quantity is related to the static energy of air parcels, and is a conserved quantity in the absence of energy sources or sinks due to surface fluxes, radiation and turbulence. As an air parcel coming from the external part of the domain moves toward the cyclone centre in the low levels, its $\theta_{\mathrm{E}}$ increases as a result of moistening and, to a lesser extent, heating by surface fluxes (Rotunno and Emanuel 1987). This leads to a strong inward increase of $\theta_{\mathrm{E}}$ in the lowest levels, from $355 \mathrm{~K}$ at $30 \mathrm{~km}$ radius to $368 \mathrm{~K}$ at $10 \mathrm{~km}$, in the region where surface winds exceed $35 \mathrm{~m} \mathrm{~s}^{-1}$. This mechanism efficiently brings energy to the base of the eyewall updraught, where latent heat is then transformed into sensible heat, and water vapour is condensed into cloud and precipitation. Some part of this high- $\theta_{\mathrm{E}}$ flow passes below the eyewall and reaches the eye, where it accumulates below the inversion layer at $2 \mathrm{~km}$ altitude. The maximum of $369 \mathrm{~K}$ below $500 \mathrm{~m}$ altitude in the eye is smaller than the value of $385 \mathrm{~K}$ obtained by Liu et al. (1999) in their simulation of Hurricane Andrew (1992), but is comparable to that deduced by Braun (2002) for simulated Hurricane Bob (1991) and by Willoughby (1998) from a sounding in the eye of Hurricane Hugo (1989). As previously observed (e.g. Hawkins and Imbembo 1976; Willoughby 1998) or obtained using numerical models (e.g. Liu et al. 1999; Braun 2002), a region of minimum $\theta_{\mathrm{E}}(<358 \mathrm{~K})$ is found between 3 and $5 \mathrm{~km}$ altitude in the eye. Above $6 \mathrm{~km}$ altitude and at radii between 10 and $20 \mathrm{~km}$, relatively high values result from the upward transport of high- $\theta_{\mathrm{E}}$ air from the bottom of the eye into the eyewall, and from the descent of upper tropospheric air along the inner edge of the eyewall.

Figure 11(a) displays an azimuth-height cross-section of tangential and radial wind, averaged over a $10 \mathrm{~km}$ radial distance centred on the local RMW. The tangentialwind maximum is found slightly to the right (at lowest levels) and to the left (aloft) of the storm track. With increasing altitude, the location of this maximum moves 

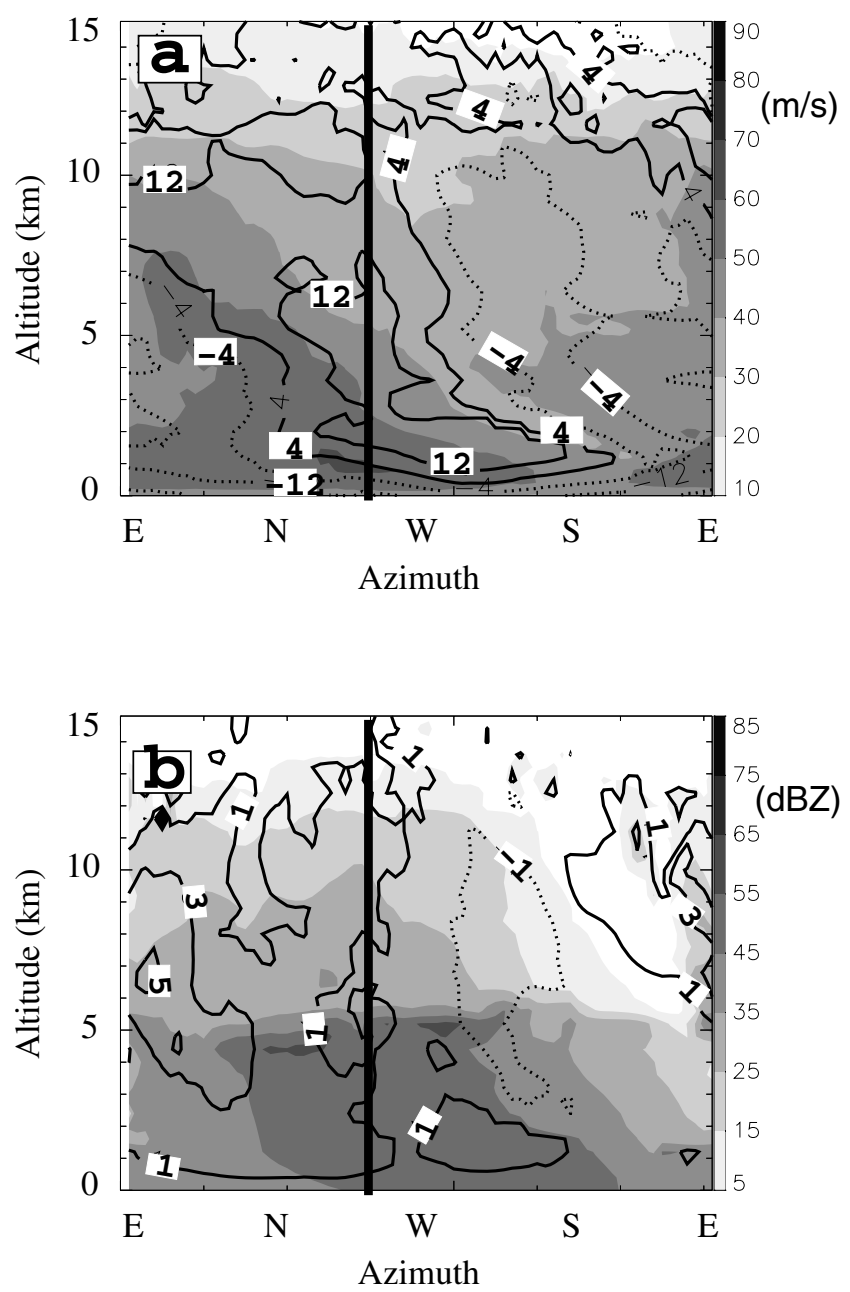

Figure 11. For the High-RDVC experiment (see text), azimuth-height distribution of: (a) tangential (contours every $10 \mathrm{~m} \mathrm{~s}^{-1}$ ) and radial (contours every $5 \mathrm{~m} \mathrm{~s}^{-1}$, dashed lines denote negative values) wind components; (b) reflectivity (grey scale, contours every $10 \mathrm{dBZ}$ ) and vertical velocity (contours every $2 \mathrm{~m} \mathrm{~s}^{-1}$, dashed lines denote negative values). The vertical line denotes the direction of storm propagation. Simulation time is 1800 UTC 22 August.

anticyclonically upstream. Hence, in the upper levels tangential wind is stronger in the trailing than in the leading part of the storm. Below $2 \mathrm{~km}$ altitude, there is an inflow in the north-eastern side and an outflow from the south-western side (part of which comes from the eye). This inflow-outflow pattern changes above $2 \mathrm{~km}$, with a deep layer of inflow in the south-eastern half of the storm and a comparable outflow from the northwest. The strongest inflow $\left(<-20 \mathrm{~m} \mathrm{~s}^{-1}\right)$ occurs near the surface, and the most intense outflow $\left(>16 \mathrm{~m} \mathrm{~s}^{-1}\right.$ ) is on the north-west side at $5 \mathrm{~km}$ altitude. At larger radii (not shown) this outflow is progressively less intense, occurs at higher altitude, and veers toward the north.

Vertical motions displayed in Fig. 11(b) show a couplet of updraughts and downdraughts, nearly aligned front to back with respect to the storm track. The strongest upward motions $\left(>3 \mathrm{~m} \mathrm{~s}^{-1}\right.$ ) extend upwind from north to east between 3 and $12 \mathrm{~km}$ altitude, with their lower part located upstream of the tangential-wind maximum. An area of 
weaker downdraughts $\left(<-1 \mathrm{~m} \mathrm{~s}^{-1}\right)$ extends south-west between 10 and $2 \mathrm{~km}$ altitude. The largest reflectivity values $(>45 \mathrm{dBZ})$ are found in the western half of the storm, downwind of the updraught on its north-eastern side. Weaker values in the eastern part are observed downstream of the downdraught. This organization, with the strongest updraughts and downdraughts at or near the limit between inflow and outflow, differs from the 'up- and out- down- and in- flow' association displayed in Liu et al. (1999). This might be related to the weaker wind shear in the present case (see below).

\section{(c) Horizontal fields}

Figure 12 shows the horizontal structure of the simulated wind components at $1800 \mathrm{~h} 22$ August. At $1 \mathrm{~km}$ altitude, the tangential velocity maximum (up to $70 \mathrm{~m} \mathrm{~s}^{-1}$ ) is located in the north-western quadrant (Fig. 12(a)). At the same altitude, the radial velocity displays an inflow from the eastern to northern side of the eyewall with an intensity of about $15 \mathrm{~m} \mathrm{~s}^{-1}$ (Fig. 12(b)). An intense outflow $\left(>20 \mathrm{~m} \mathrm{~s}^{-1}\right.$ ) spreads southwestwards from the eye. The vertical velocity field at $3 \mathrm{~km}$ altitude (Fig. 12(c)) reveals that the area of upward motion in the south-western part of the eyewall is correlated with the observed outflow from the eye, suggesting that, in this region, air parcels are first rapidly accelerated outwards, then injected in the eyewall and transported upwards. Such a strong coupling between low-level outflow from the eye and upward motion has also been observed by Braun (2002) who suggested that this air probably does not originate in the eye, but more probably comes from outside of the eyewall, moves with the inflow to the inner eyewall edge, then quickly moves back outward. Slightly more intense updraughts $\left(\approx 6 \mathrm{~m} \mathrm{~s}^{-1}\right)$ are found in the northern part of the eyewall, in relation to the strong inflow there. Intense $\left(> \pm 5 \mathrm{~m} \mathrm{~s}^{-1}\right)$ updraughts and downdraughts are also found in association with convective rainbands at 30 to $90 \mathrm{~km}$ from the storm centre.

The hodograph of the total horizontal wind (averaged within $3^{\circ}$ latitude from the storm centre) from 900 to $300 \mathrm{hPa}$ (Fig. 13) shows that the simulated tropical cyclone is embedded in relatively weak south-westerly wind shear $\left(4 \mathrm{~m} \mathrm{~s}^{-1}\right.$ between 700 and $300 \mathrm{hPa}$ ). It is possible that the region of upward motion on the north-eastern side of the storm is related to the environmental vertical shear vector, since numerous observational (e.g. Franklin et al. 1993; Gamache et al. 1997; Black et al. 2002; Corbosiero and Molinari 2002) and modelling (e.g. Frank and Ritchie 1999; Rogers et al. 2003) studies have shown a tendency for hurricane-strength vortices to develop upward motion on the down-shear side of the storm. The observed vertical velocity pattern could also, at least partially, be related to the asymmetric boundary-layer convergence mechanism (Shapiro 1983), in which convection is enhanced in front of, or slightly to the right of, the storm track, i.e. in its northern and north-eastern parts for the present case (Fig. 12). These asymmetries are also related to changes in the direction of storm propagation. Between 1600 and $1800 \mathrm{~h} 22$ August, the simulated storm motion veered by about $20^{\circ}$ toward the west (the direction of propagation was from $140^{\circ}$ at $1600 \mathrm{~h}$, and $160^{\circ}$ by $1800 \mathrm{~h}$ ). At $1800 \mathrm{~h}$, the $2 \mathrm{~h}$ accumulated precipitation (not shown) indicates that most of the rain fell in the western and northern quadrants. Afterward, the change in the direction of motion caused a $90^{\circ}$ shift of the maximum of accumulated precipitation, then occurring in the south and south-west quadrants. The hodograph also explains the asymmetric structure of tangential and radial winds (Fig. 11). It is consistent with the inflow (outflow) on the south-eastern (north-western) side at mid-levels, gradually turning to the southern (northern) side with height. The tangential winds, being $90^{\circ}$ out of phase with the radial winds, also support this analysis.

The structure and evolution of Hurricane Bret prior to landfall was well captured by the WSR-88D radar at Brownsville (Texas). The simulated reflectivity structure at 

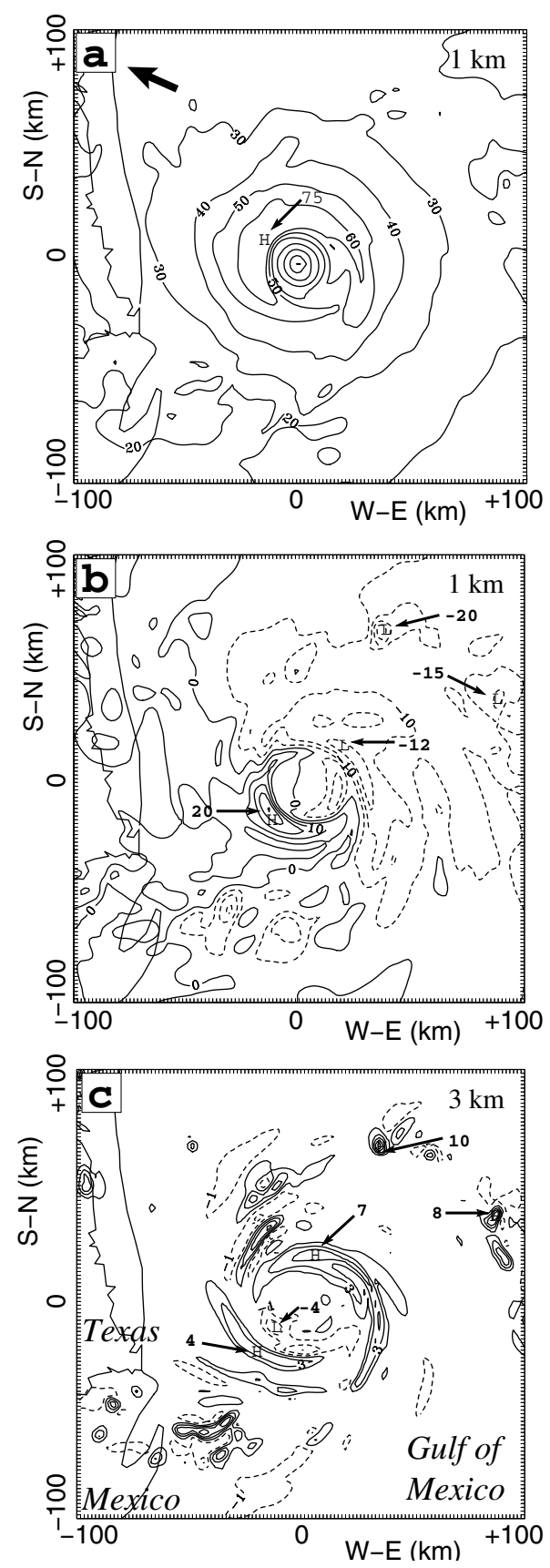

Figure 12. For the High-RDVC experiment (see text), horizontal distribution in a domain $200 \mathrm{~km} \times 200 \mathrm{~km}$ of: (a) tangential wind (contours every $10 \mathrm{~m} \mathrm{~s}^{-1}$ ) at $1 \mathrm{~km}$ altitude; (b) radial wind (contours every $10 \mathrm{~m} \mathrm{~s}^{-1}$, dashed lines denote negative values) at $1 \mathrm{~km}$; (c) vertical velocity (contours every $2 \mathrm{~m} \mathrm{~s}^{-1}$, dashed lines denote negative values) at $3 \mathrm{~km}$. Simulation time is 1800 UTC 22 August. 


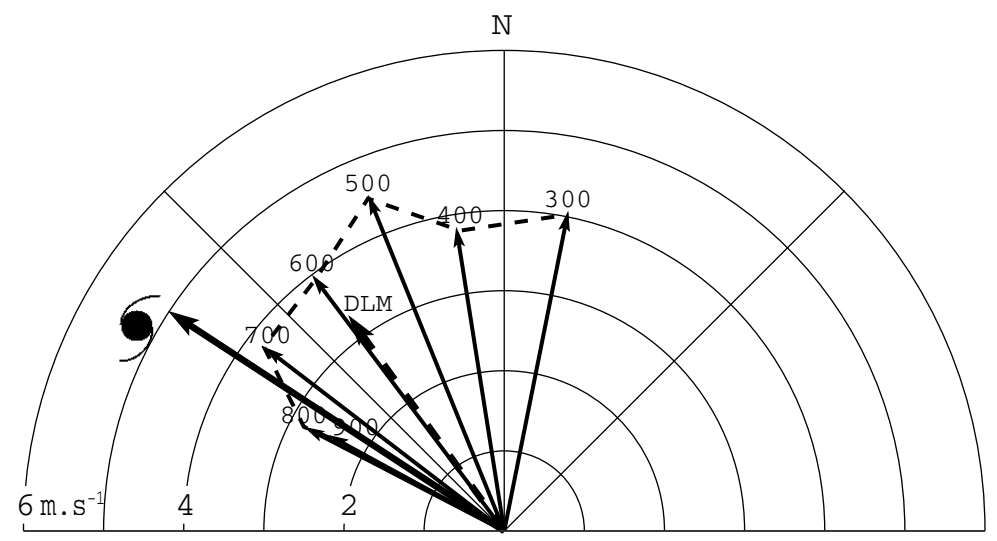

Figure 13. For the High-RDVC experiment (see text), hodograph of the area-averaged (within a radius of $3^{\circ}$ of latitude from the storm centre) wind between 900 and $300 \mathrm{hPa}$, for the simulated storm at 1800 UTC 22 August. Also indicated are the density-weighted mean (dashed arrow, DLM) and the storm propagation (solid arrow, hurricane symbol).

$1900 \mathrm{~h} 22$ August can be compared to the ground-based radar observations of Hurricane Bret at $1759 \mathrm{~h}$. The observed reflectivity values at $0.5^{\circ}$ elevation (Fig. 14(a)) display maxima of 40-50 dBZ associated with deep convection in the south-western part of the storm. The simulated reflectivity field at $1 \mathrm{~km}$ altitude shows many similarities, especially in the inner core region, however, with slightly larger values $(>52 \mathrm{dBZ})$ and wider radial extent in the western part of the eyewall (Fig. 14(b)). Although MésoNH does not accurately reproduce the outward extension of moderate precipitation ( $\leq 35 \mathrm{dBZ}$ ), the simulated field correctly shows convective rainbands at 80-90 km from the storm centre to the north-east and south-west. From the microphysical point of view, the observed differences between ground-based radar and simulated reflectivity values (as well as comparisons with microwave brightness temperature observations from space, Burlaud et al. (2002)) could indicate that hydrometeors produced by MésoNH do not stay aloft long enough, which could limit the radial expanse of the modelled storm.

\section{(d) Inner core asymmetries}

Bret was a small but intense storm which strengthened rapidly during the evening of 21 August. Its central pressure dropped from 975 to $950 \mathrm{hPa}$ and the maximum 1minute surface wind increased from 45 to $60 \mathrm{~m} \mathrm{~s}^{-1}$ in the $6 \mathrm{~h}$ ending $0000 \mathrm{~h} 22$ August (Lawrence et al. 2001). A precursory sign for rapid deepening of a hurricane can be the presence of enhanced potential vorticity (PV) in the eyewall due to diabatic heating, with weaker vorticity in the eye and at larger radii, which leads to an unstable radial gradient of PV on which PV waves - the generalization of Rossby waves - can propagate. As a result of barotropic instability near the radius of maximum wind, an annulus of enhanced vorticity evolves into a series of mesovortices that can be maintained for many rotation periods (e.g. Schubert et al. 1999; Kossin and Schubert 2001). The horizontal flow associated with such a configuration typically follows a number of straight lines that give the streamlines an elliptical or polygonal aspect, which evolves as the mesovortex configuration evolves. Through wave-mean flow and wave-wave interactions, PV is then progressively advected toward the eye region and at larger radii, and the vortex intensifies. 

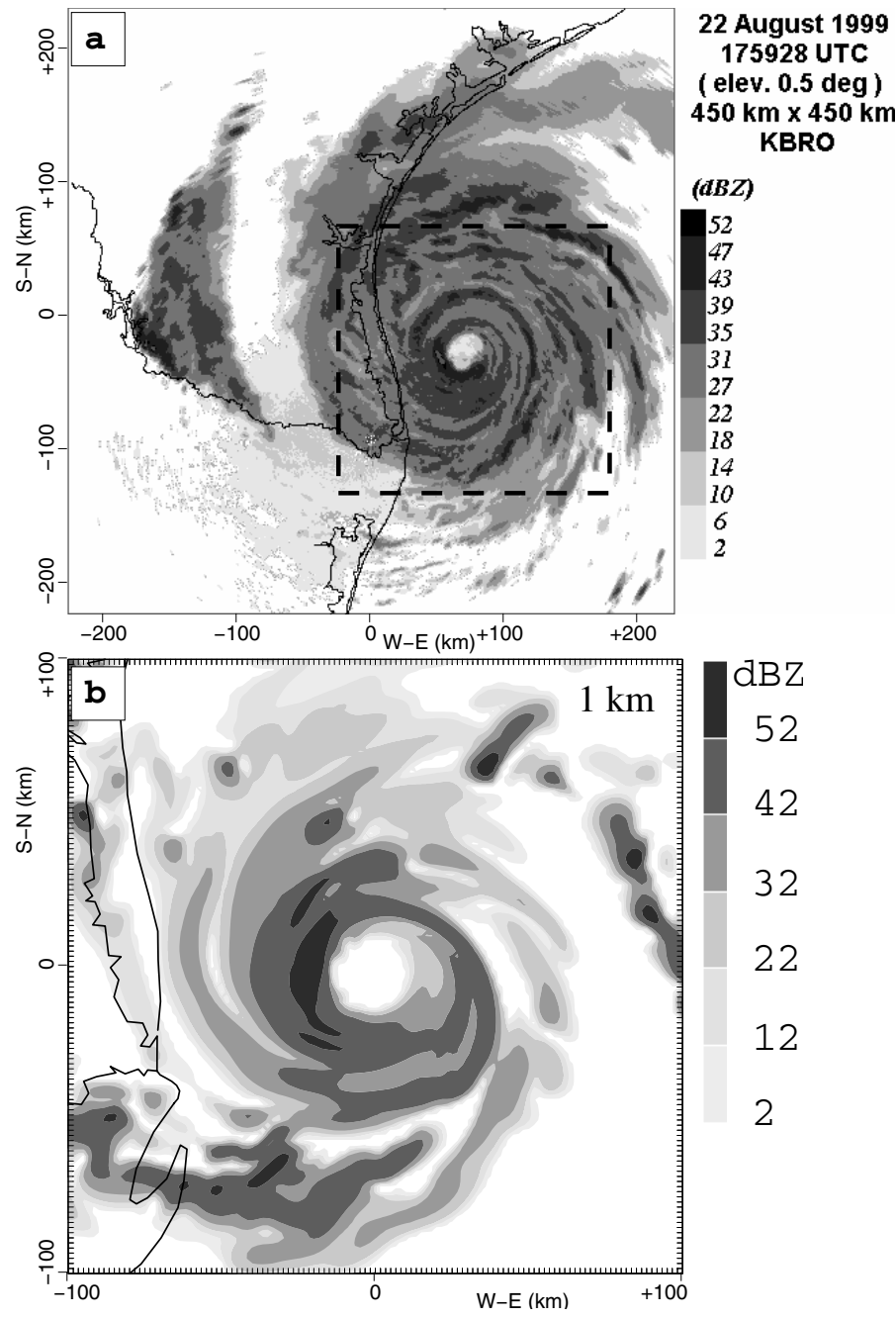

Figure 14. (a) Reflectivity field at $0.5^{\circ}$ elevation in a domain of $450 \mathrm{~km} \times 450 \mathrm{~km}$ from the WSR-88D radar at Brownsville (Texas, USA) at 1759 UTC 22 August (the dashed line contour denotes the domain of (b)); (b) for the High-RDVC experiment (see text), simulated reflectivity values at $1 \mathrm{~km}$ altitude in a domain of $200 \mathrm{~km} \times 200 \mathrm{~km}$ at 1900 UTC 22 August.

Cyclonically rotating eyewalls with various elliptical or polygonal shapes have been documented in intense hurricanes with central pressures less than $950 \mathrm{hPa}$ (e.g. Lewis and Hawkins 1982; Muramatsu 1986; Kuo et al. 1999; Reasor et al. 2000; Braun 2002). With regard to Hurricane Bret on 21 August 1999, although the main characteristics of the reflectivity field were conserved throughout the observing period (2010-2310 h) with strongest values in the north-western quadrant, detailed observations of the central region revealed irregular polygonal patterns along the inner edge of the eyewall (as previously noted by Kossin and Schubert 2001). For example, a series of 3-minute reflectivity composites from the horizontally scanning $5 \mathrm{~cm}$ lower fuselage (LF) radar data from 2237 to 2255 h (Fig. 15), when the NOAA P3 aircraft was inside Bret's eye, shows an approximately pentagonal shape rotating cyclonically with an estimated 

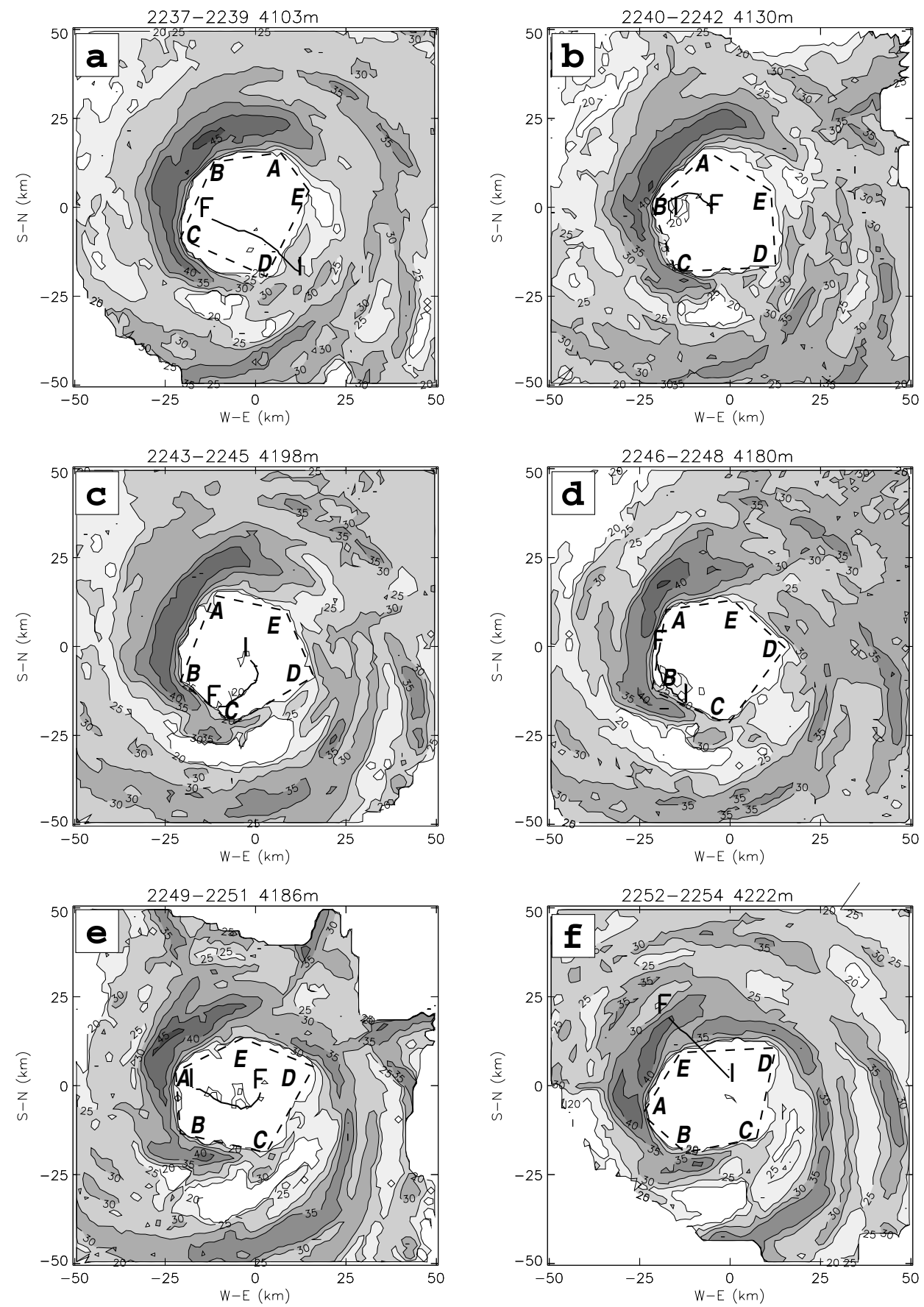

Figure 15. Horizontal reflectivity composite from the NOAA P3 aircraft LF radar data in domains of $100 \mathrm{~km} \times$ $100 \mathrm{~km}$, the northward storm advection of $5.6 \mathrm{~m} \mathrm{~s}^{-1}$ being taken into account, at: (a) 2237-2239, (b) 2240-2242, (c) 2243-2245, (d) 2246-2248, (e) 2249-2251, (f) 2252-2254, on 21 August 1999 (all times are UTC). Shading starts from $20 \mathrm{dBZ}$ and increases every $5 \mathrm{dBZ}$. I and F denote the initial and final locations of the NOAA P3 for each period. A, B, C, D, E denote the apices of a pentagon. See text for details. 
period of about 50 minutes. Pentagonal and hexagonal shapes were also revealed by high-resolution LF radar composites during the three previous eye crossings (2022$2027 \mathrm{~h}, 2108-2112 \mathrm{~h}, 2153-2157 \mathrm{~h}$ ) with rotation periods ranging from 45 to 55 minutes (not shown). Considering a mean eye diameter of $35 \mathrm{~km}$, this is equivalent to an azimuthal phase speed of 33 to $41 \mathrm{~m} \mathrm{~s}^{-1}$, which is slightly slower than the EVTDderived maximum azimuthal mean tangential-wind speed of $42 \mathrm{~m} \mathrm{~s}^{-1}$ at $4 \mathrm{~km}$ altitude. (Note however that the EVTD analysis was conducted with Doppler data collected between 2010 and $2310 \mathrm{~h}$ as the storm was intensifying, so the actual maximum wind between 2237 and $2255 \mathrm{~h}$ might have been slightly stronger.) Following Guinn and Schubert (1993), a wave number-five or -six Rossby wave associated with the observed pentagonal or hexagonal form would move at $4 / 5$ or $5 / 6$ the speed of the basic-state tangential flow, which agrees fairly well with the observed values. Unfortunately, as discussed by Reasor et al. (2000) who used dual-aircraft data in their study of Hurricane Olivia (1994), a detailed analysis of the associated asymmetries in the wind field is difficult, due to the minimum 30-minute time resolution to retrieve the hurricane circulation from airborne Doppler data.

As seen in Fig. 9, after an initial period during which the model progressively adapted to cyclonic conditions, the high-RDVC simulated storm underwent substantial intensification, with an increase of the azimuthal mean maximum wind from 45 to $66 \mathrm{~m} \mathrm{~s}^{-1}$ and a drop of the minimum pressure from $975 \mathrm{hPa}$ at $0600 \mathrm{~h} 22$ August to $946 \mathrm{hPa}$ at $1800 \mathrm{~h}$. This bears some resemblance to the strengthening phase of Hurricane Bret on the evening of 21 August 1999, and it is interesting to check whether asymmetries were present in the core region of the simulated storm. Figure 16 shows a series of horizontal contours of the simulated radar reflectivity and tangential velocity interpolated at $900 \mathrm{hPa}$ in a domain of $100 \mathrm{~km} \times 100 \mathrm{~km}$ centred on the minimum surface pressure, every 30 minutes from 1500 till $1730 \mathrm{~h} 22$ August. The eye of the simulated storm appears elliptical with minor and major axes of 15-18 and 30-33 km, respectively, and it rotates cyclonically in time with a period of about 75 minutes. This is more than twice the circulation period of 35 minutes for an air parcel advected at $20 \mathrm{~km}$ radius (RMW) and $60 \mathrm{~m} \mathrm{~s}^{-1}$ tangential wind, in fair agreement with the theoretical phase speed of a wave number-two vortex Rossby wave.

The difference between the asymmetries in the core region of the observed and simulated storms could be related to different radial profiles of PV. Indeed, a linear stability analysis of an annular region of enhanced vorticity reveals a preference for higher wave numbers as the ring becomes thinner (Schubert et al. 1999). Likewise, Nolan and Montgomery (2002) showed that an 'intense' vortex with a thin $(14 \mathrm{~km}$ width) annulus of high vorticity $\left(>2.65 \times 10^{-3} \mathrm{~s}^{-1}\right)$ is most unstable to wave numbers three and four, while the most unstable mode of a 'moderate' vortex with a wider $(23 \mathrm{~km})$ and weaker $\left(>1.25 \times 10^{-3} \mathrm{~s}^{-1}\right)$ vorticity maximum occurs for wave number two, and the less stable mode of a 'weak' vortex ( $37 \mathrm{~km}$ width, $>0.75 \times 10^{-3} \mathrm{~s}^{-1}$ ) is for wave number one. Figure 17 shows a comparison between the azimuthal mean radius-height distribution of PV derived from the EVTD analysis (using temperature perturbations retrieved as in Viltard and Roux 1998) and from the numerical simulation at $1600 \mathrm{~h} 22$ August. The overall structures are relatively similar, with largest values at radii smaller than RMW and below $10 \mathrm{~km}$ altitude, but there are some significant differences. Below $6 \mathrm{~km}$ altitude, radial decrease of the EVTD-derived PV toward the storm centre is larger than the simulated one. Although there are some uncertainties on the reliability of the EVTD winds and the derived radial gradient of PV at small radii $(\leq 10 \mathrm{~km})$ due to the lack of hydrometeors in Bret's eye, the significantly narrower zone of high PV in the low to mid-troposphere could explain the probable presence 

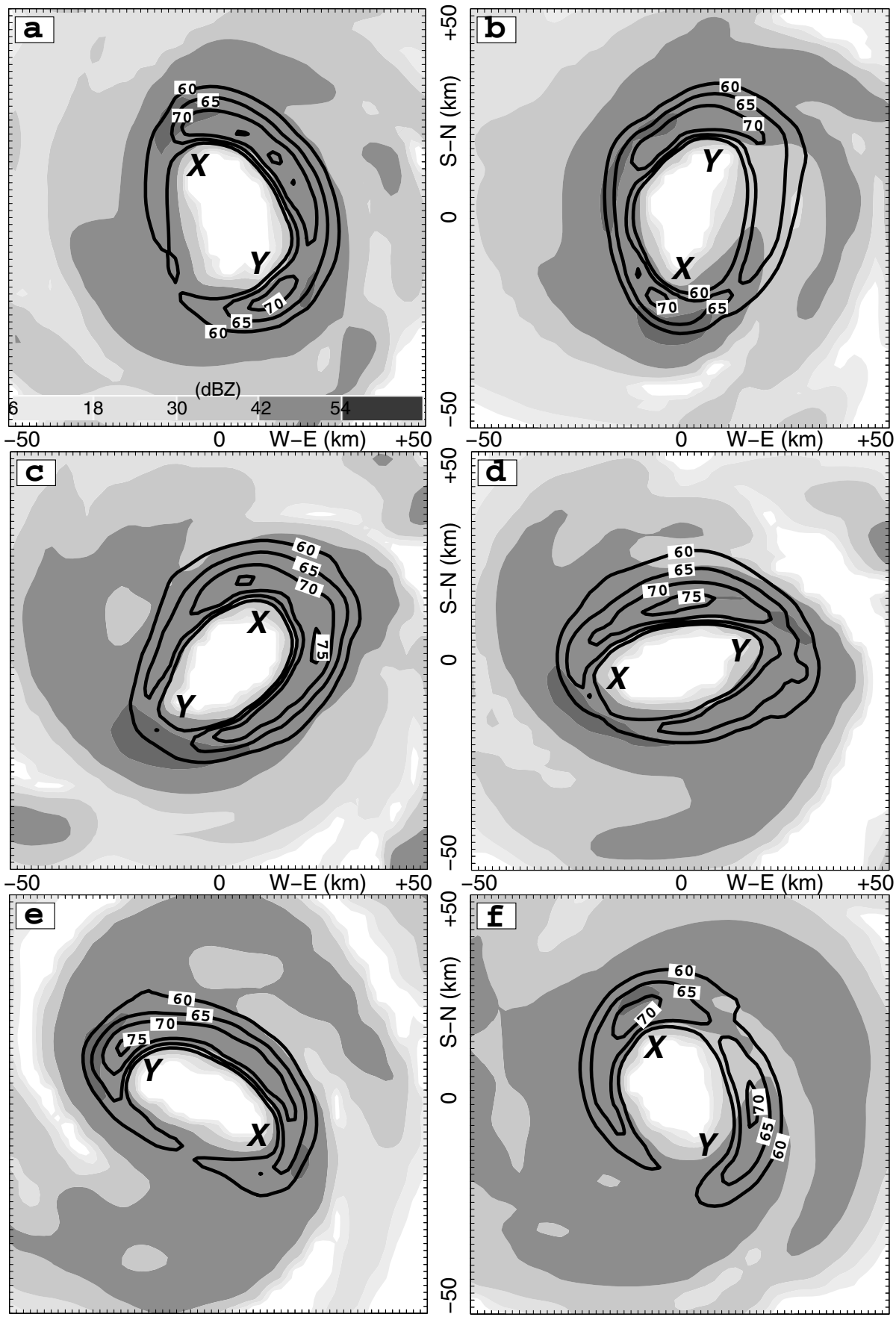

Figure 16. For the High-RDVC experiment (see text), simulated reflectivity values (shading starts from $6 \mathrm{dBZ}$ and increases every $12 \mathrm{dBZ}$ ) and wind intensity (contour step is $5 \mathrm{~m} \mathrm{~s}^{-1}$, starting from $60 \mathrm{~m} \mathrm{~s}^{-1}$ ) interpolated at $900 \mathrm{hPa}$ in domains of $100 \mathrm{~km} \times 100 \mathrm{~km}$ centred on the location of the minimum surface pressure at: (a) 1500, (b) 1530, (c) 1600, (d) 1630, (e) 1700, (f) 1730, 22 August 1999 (all times are UTC). X and Y denote the apices of the elliptical eye. 

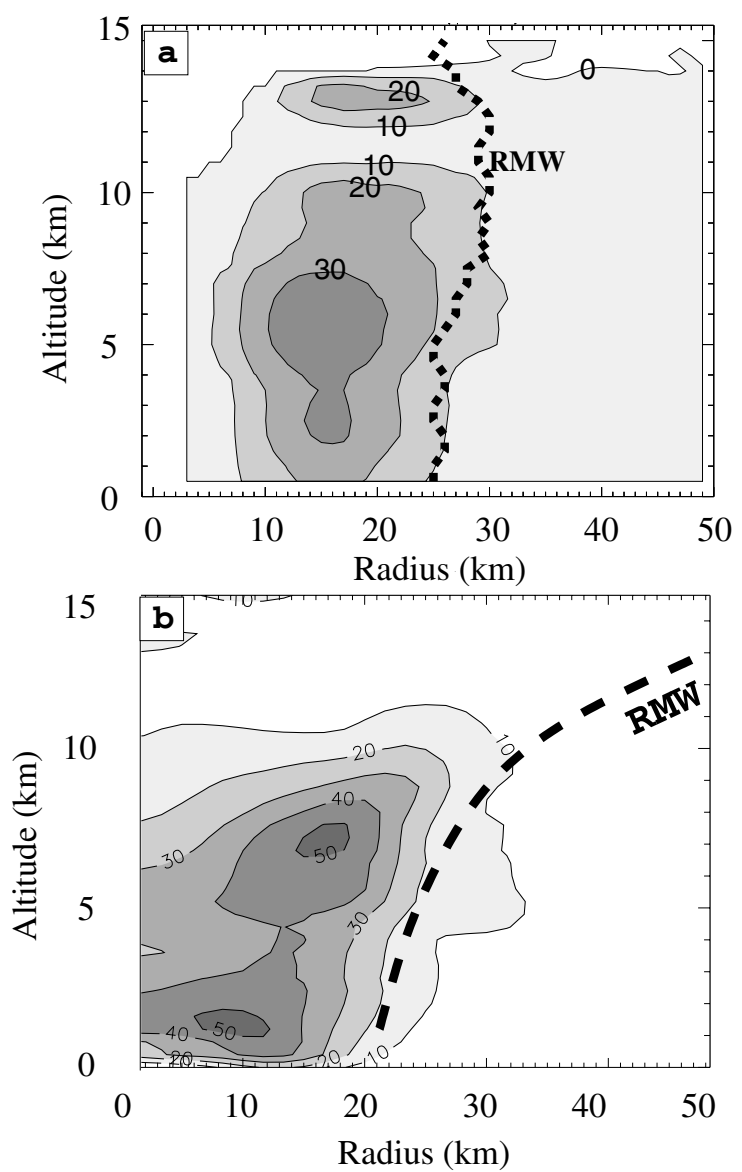

Figure 17. Radius-height distribution of potential vorticity (in PV units, $10^{-6} \mathrm{~m}^{2} \mathrm{~s}^{-1} \mathrm{~K} \mathrm{~kg}^{-1}$ ) from: (a) the EVTD-derived wind and temperature fields; (b) the High-RDVC experiment simulated fields at 1600 UTC. The dashed line denotes the position of the radius of maximum wind. See text for details.

of high-wave number asymmetries in the observed eyewall, while a wave number-two asymmetry is found in the simulated storm.

Figure 18 displays the evolution of the mean PV between 900 and $600 \mathrm{hPa}$. The elliptical PV structure rotates cyclonically with the reflectivity field, and it shows a doughnut shape with largest values along the inner edge of the eyewall and smaller ones in the eye and at larger radii. This is an unstable situation, where vortex Rossby waves can develop and progressively relax this annular ring of high PV into a stable monopolar distribution (Schubert et al. 1999). To maintain the PV ring structure, latentheat release in the eyewall continuously generates positive PV anomalies below the level of maximum heating (Chen and Yau 2001). The coupling between the vortex Rossby waves (which transport PV from the eyewall to the eye then spinning up the storm) and the diabatic source, occurs through the relation between wave-induced perturbations of the horizontal flow in the lower troposphere and the vertical motions caused by the associated convergence/divergence patterns (Wang 2002a). With time, the simulated radial structure of PV evolves toward a more stable distribution with the central minimum progressively filling in. 


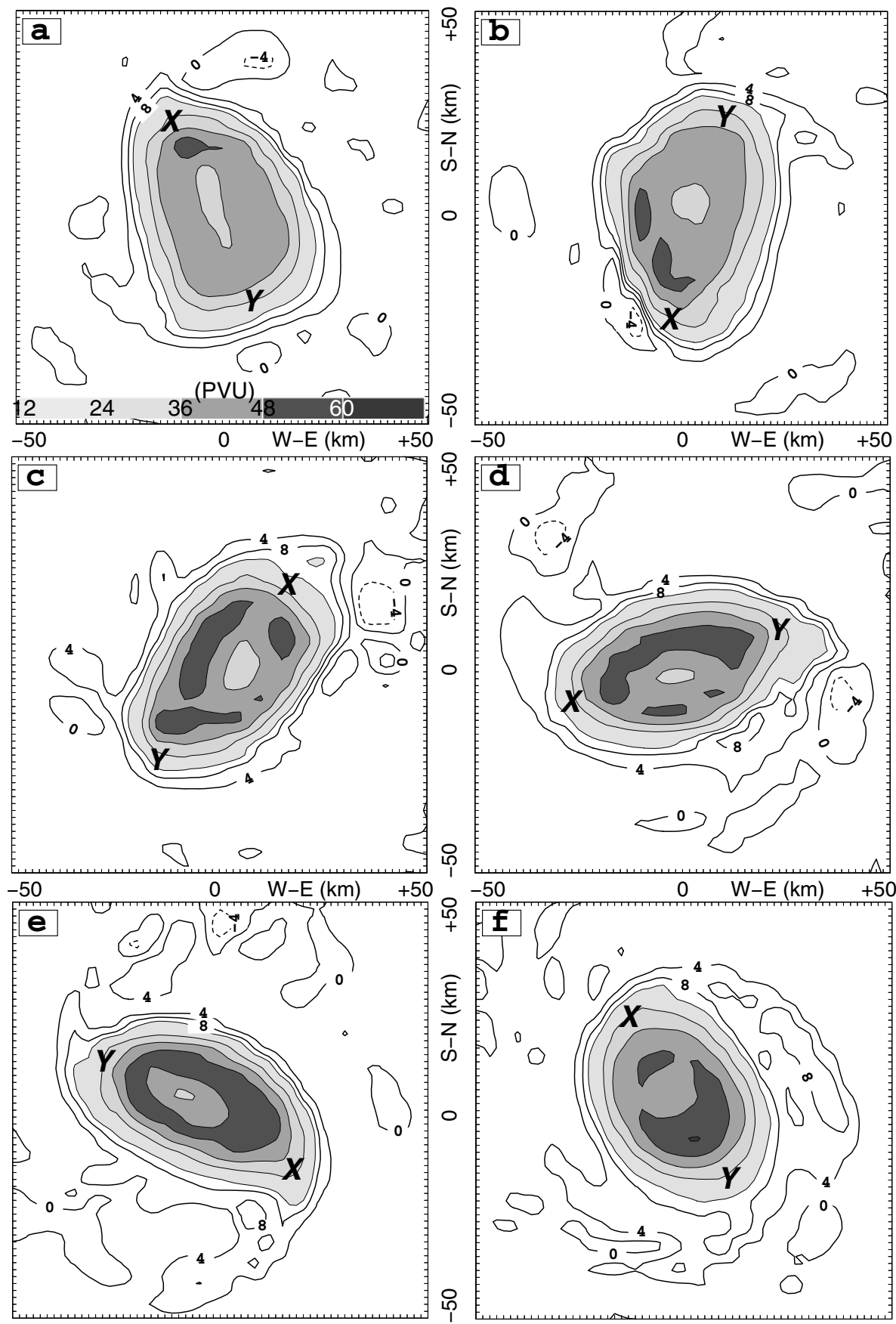

Figure 18. As in Fig. 16, except for the mean potential vorticity (PV) in the layer 900-600 $\mathrm{hPa}$. Contour step is $4 \mathrm{PV}$ units (1 PV unit $\left.=10^{-6} \mathrm{~m}^{2} \mathrm{~s}^{-1} \mathrm{~K} \mathrm{~kg}^{-1}\right)$. Shaded zones denote regions with PV larger than $12,24,36$ and $48 \mathrm{PV}$ units, respectively. 

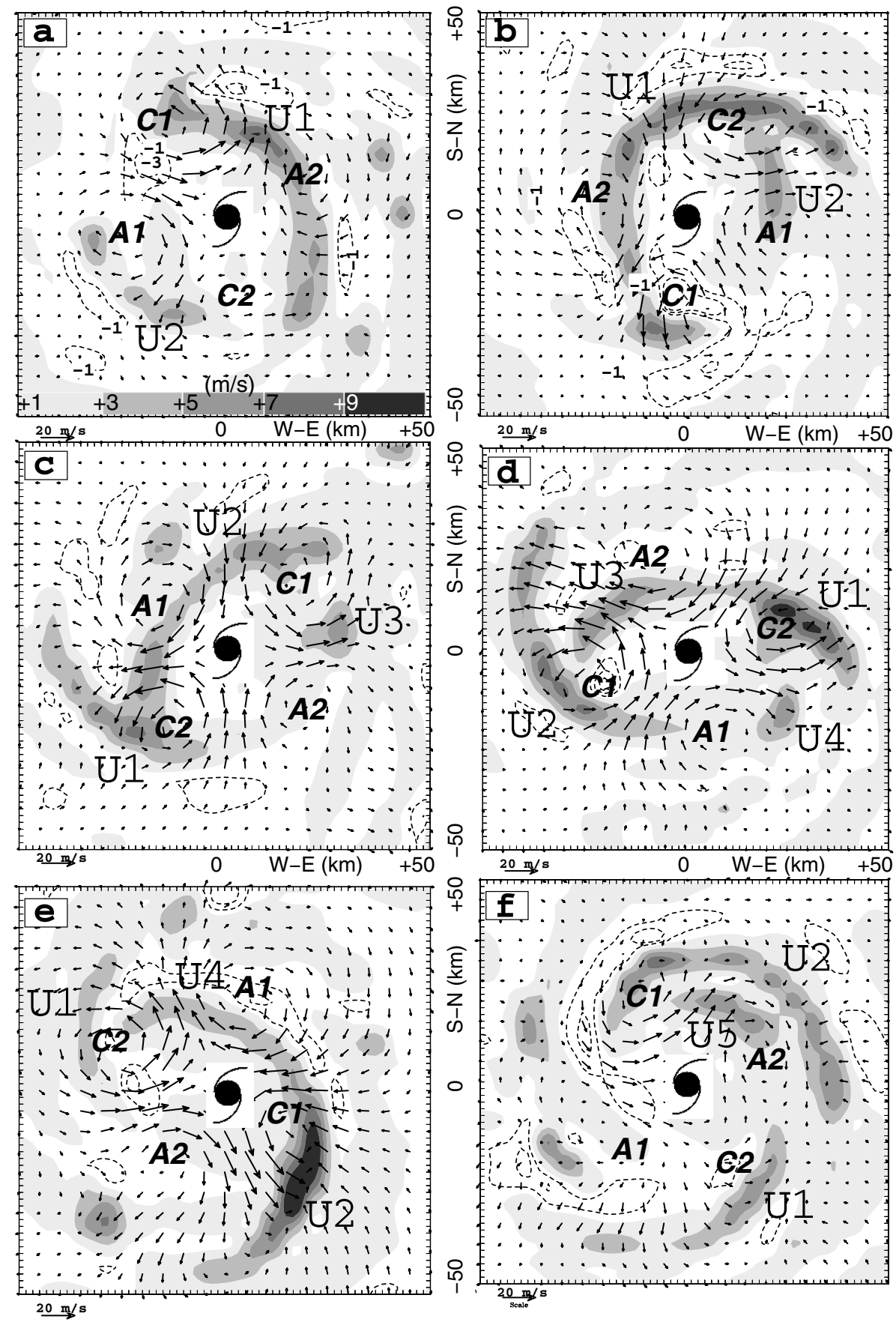

Figure 19. As in Fig. 16, except for the density-weighted asymmetric horizontal wind (see text for definition) in the layer 900-600 hPa (arrows) and vertical velocity at $600 \mathrm{hPa}$ (contour step is $2 \mathrm{~m} \mathrm{~s}^{-1}$, dashed lines denote negative values, shaded zones indicate positive values). A1, A2, C1, C2 denote the anticyclonic and cyclonic gyres; U1 to U5 indicate the successive updraughts. 


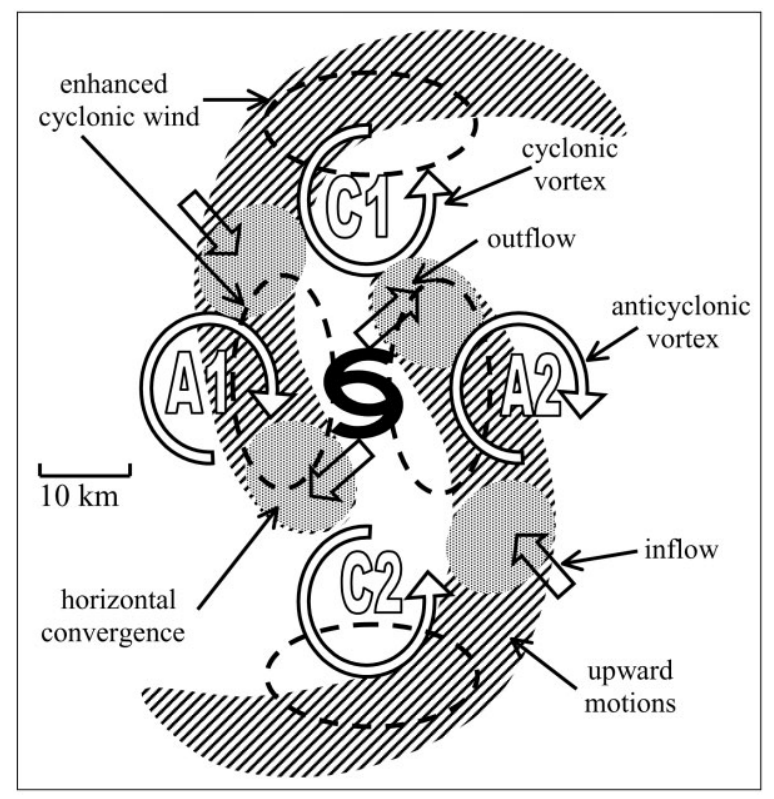

Figure 20. Schematic of the horizontal and vertical wind perturbations induced by wave number-two vortices in the eyewall region.

As seen in Fig. 19, which displays the density-weighted mean asymmetric horizontal wind (total wind minus propagation speed, mean wind and symmetric vortex) in the layer $900-600 \mathrm{hPa}$ and vertical velocity at $600 \mathrm{hPa}$, the elliptical shape of the eyewall reflectivity (Fig. 16) is associated with a well-defined wave number-two wind perturbation, with an azimuthal shift of about $30^{\circ}$ resulting from cyclonic advection during hydrometeor fall. This vortex Rossby-wave structure, with two cyclonic gyres (C1 and $\mathrm{C} 2$ in Fig. 19) and two anticyclonic gyres (A1 and A2), dominated the asymmetric wind field from 1500 till $1730 \mathrm{~h}$, after which it dissipated in agreement with the more stable radial distribution of PV (Fig. 18(f)). Compared with the previous analyses by Chen and Yau (2001), Braun (2002), Wang (2002a,b) and Chen et al. (2003) the higher spatial resolution here- $1.67 \mathrm{~km}$ instead of 5 and $6 \mathrm{~km}$-provides more details on the characteristics and coupling of the wave-induced horizontal and vertical flow (Braun (2002) used a resolution of $1.3 \mathrm{~km}$ for $6 \mathrm{~h}$ out of $72 \mathrm{~h}$ of the simulated time).

A comparison between Figs. 16 and 19 shows that regions of enhanced or reduced tangential wind and radar reflectivity in the eyewall are related to the presence of cyclonic and anticyclonic vortices. Upward motions (U1 to U5 in Fig. 19) successively form in the two zones of outflow and enhanced convergence on the inner edge of the wave region at $16-20 \mathrm{~km}$ radii, between the cyclonic and anticyclonic gyres $(\mathrm{C} 2-\mathrm{A} 1$ and $\mathrm{C} 1-\mathrm{A} 2$ in Fig. 19), downstream regions of enhanced cyclonic tangential wind. This again confirms that the sporadic injection of high- $\theta_{\mathrm{E}}$ air, from low-level air being dragged into the eye then quickly moving back outward, plays an important role in modulating hurricane intensity (Liu et al. 1999; Braun 2002). These upward motions develop outward with a radial phase speed of 5-6 $\mathrm{m} \mathrm{s}^{-1}$, and anticyclonically with respect to the Rossby wave gyres at $60-90^{\circ} \mathrm{h}^{-1}$. They intensify substantially in the zones of enhanced convergence and inflow on the outer edge of the wave region at $22-26 \mathrm{~km}$ radii, between the anticyclonic and cyclonic gyres $(\mathrm{C} 1-\mathrm{A} 1$ and $\mathrm{C} 2-\mathrm{A} 2$ in Fig. 19), and progressively form more or less continuous bands up to $100 \mathrm{~km}$ long. 
These features are summarized in Fig. 20, which shows a schematic of the horizontal and vertical wind perturbations induced by wave number-two vortices in the eyewall region. These outward propagating spiral bands, which emanate from the eyewall region, are progressively sheared by the differential rotation of the vortex and they transport PV outwards (Guinn and Schubert 1993; Montgomery and Kallenbach 1997). Downward motions are observed on the inner and outer sides of these updraughts. The intensity of upward motions decreases and the spiral patterns begin to dissipate when the vortices become less clearly defined (Fig. 19(f)).

The upward motions are associated with local reflectivity (Fig. 16) and PV (Fig. 18) maxima which show similar, though less marked, spiral patterns. The wind distribution (Fig. 16) is modulated by two factors: (i) the enhanced cyclonic flow on the outer (inner) edge of cyclonic (anticyclonic) gyres which gives the region of strongest winds an elliptical shape, and (ii) local and sporadic intensification associated with updraughts. Contribution (i) rotates around the eye with the same period as the vortex Rossby waves and the elliptical reflectivity field, while contribution (ii) propagates anticyclonically, more or less regularly, with respect to the wave gyres, as updraughts U1 to U5 develop radially and anticyclonically outward. Both effects combine to yield an almost stationary wind maximum in the north to north-eastern quadrant of the eyewall. These factors appear to be dominated by wave numbers zero and one, and modulated by higher wave numbers, whereas the stationary maximum is determined predominantly by wave number one.

\section{SUMMARY AND CONCLUDING REMARKS}

An original initialization technique has been used to study the structure, evolution and propagation of Hurricane Bret on 22-23 August 1999 using the MésoNH nonhydrostatic multi-nested numerical model. This case-study was selected because of the availability of airborne Doppler radar and dropsonde observations from the NOAA annual Hurricane Field Program involving P3 and G-IV aircraft. Improvement of the observed environmental humidity through better analysis of the drosponde data is necessary to correctly simulate the hurricane. Likewise, the ill-defined and weak analysed cyclone must be replaced by a smaller and stronger vortex derived from an EVTD analysis of Doppler radar observations. Only the symmetric (wave number 0) component of tangential velocity is retained from the radar data, and from this field the symmetric temperature perturbation field is deduced from thermal-wind balance.

Of course, it would be better to keep information on vortex asymmetries (wave number one and higher), but this would require the use of a less simple relation, such as 'asymmetric balance' (Shapiro and Montgomery 1993) to derive temperature perturbations from tangential velocity. Moreover, there is no guarantee that the necessary analytic extrapolation would provide reliable information on the asymmetric fields at radii beyond the range of radar observations. Likewise, taking into account the secondary (radial and vertical) circulation would certainly facilitate the initial evolution of the simulated storm. It must however be emphasized that most of the hurricane inflow occurs in a shallow $(<1 \mathrm{~km})$ layer above the ocean surface where airborne radar observations are difficult to obtain (this is even more problematic for coastal ground-based radars), so that Doppler-derived radial and vertical velocities might not be accurate enough. However, it should be possible to include a parametrized low-level jet in the wind analysis so as to represent the ill-observed radial inflow close to the surface. Another problem with the secondary circulation is that, to fit the balanced primary (tangential) circulation, it 
must obey an Eliassen-type elliptic equation with a priori unknown heat and momentum source terms (Shapiro and Willoughby 1982). Likewise, so as to take into account storm evolution during observations, it would be necessary to fit the analysed kinematic and thermodynamic evolution to the advective and source terms of balanced equations.

In comparison with a control run, that includes a poorly resolved vortex and its environment from the large-scale analysis in a high-resolution non-hydrostatic model, the inclusion of dropsonde and radar-derived data substantially improves the track and intensity of the simulated storm. In particular, the time necessary to reach hurricane amplitude is considerably reduced. Another important point is that the better agreement with the observed track, which is probably due to the more vertically extended radarderived vortex compared to the relatively shallow vortex from the global analysis, leads to more realistic interactions with the tropospheric environment. Such an improvement in forecast track can be very important in situations where a storm is close to landfall (e.g. 12-24 h from landfall).

Our approach is certainly simpler than the BDA scheme (Zou and Xiao 2000) which takes advantage of the built-in four-dimensional variational data assimilation (4D-VAR) framework of the MM5 model. However, as expressed by Pu and Braun (2002), although many successful hurricane simulations have been conducted using simpler bogus vortices for model intialization, the most important issue is certainly the availability of a dynamically and thermodynamically consistent initial vortex, compatible with the resolution, dynamics and physics of the prediction model. That was the goal of this paper, and there is no doubt that it can also be achieved through 4D-VAR. However, use of a 4D-VAR scheme is very computationally intensive, requiring a great deal of computing time just to produce an appropriate initial vortex. Furthermore, the necessary parameters for correctly running a variational scheme, i.e. the error covariance matrices, are not currently known for the high-resolution radar data we are using. Therefore, until computing power is significantly enhanced and the necessary relationships determined, the technique presented here provides a viable, simpler alternative to variational techniques.

Despite some advantages of using a radar-derived bogusing technique such as that presented here, care must be taken in using the radar data. For example, the use of airborne or ground-based radar data can lead to disappointing results due to specific measurement uncertainties and errors such as velocity folding, reflectivity attenuation, volume averaging, and side lobe contamination. Moreover, the combination of instantaneous local measurements and finite sampling time makes it difficult to separate the mesoscale structure and slow evolution from the more turbulent and unbalanced small-scale perturbations in a Doppler-derived wind field. Hence, we feel it is probably worth developing techniques to pre-process radar data, so as to ensure that only the balanced structure and evolution is taken into account for model initialization using bogusing techniques or 4D-VAR.

At the mature stage, the azimuthal mean kinematic and thermodynamic features generated by MésoNH bear significant resemblance to those derived from in situ and radar observations, and from previous numerical modelling results. An analysis of the asymmetric features in the inner core during the intensification phase reveals the presence of a rotating elliptical eyewall. The associated perturbation of the horizontal wind is apparently related to a wave number-two vortex Rossby wave, generated by an unstable radial gradient of PV. Coupling between the waves and eyewall convection results from the successive generation of updraughts in the two zones of outflow from the eye, and enhanced convergence between the anticyclonic and cyclonic gyres, followed by outward development forming spiral rainbands where latent-heat release generates anomalies of positive PV below the level of maximum heating. 
The lack of a prognostic description of the upper ocean layers in MésoNH (and other non-hydrostatic mesoscale models) certainly leads to an overestimate of storm intensity. It is well known that tropical cyclones, especially those with strong surface winds and slow movement, have a noticeable impact on the circulation in the ocean surface and sub-surface, and that the resulting decrease of SST can limit storm intensification. Moreover, the fact that the effect of sea-spray evaporation and of dissipative heating (Bister and Emanuel 1998; Zhang and Altshuler 1999) are not taken into account in the MésoNH oceanic boundary-layer parametrization certainly brings some uncertainty in the intensity of the simulated storm.

\section{ACKNOWLEDGEMENTS}

MM J. Escobar and D. Gazen, Ms J. Duron, Drs J. P. Pinty and P. Mascart are thanked for their help and advice in the use of MésoNH. We are also indebted to Dr M. Chong for his insight on filtering. Airborne Doppler data from Hurricane Bret were kindly provided by Hurricane Research Division (NOAA/AOML/HRD, Miami, Fla., USA). The NOAA/Aircraft Operation Center crews onboard P3 and G-IV aircraft must be thanked for their dedication. The computations were performed at the Institut du Développement et des Ressources en Informatique Scientifique (IDRIS) through project 020591 . Financial support for this study has been provided by grants from the Programme Atmosphère Océan Multiéchelles of the Institut National des Sciences de l'Univers et de l'Environnement. Part of this work was realized during Robert F. Roger's 6-month stay in Laboratoire d'Aérologie (Toulouse, France), with financial support from Cooperative Institute for Marine and Atmospheric Studies (University of Miami, Fla., USA) and Centre National de la Recherche Scientifique (Paris, France). Comments made by the anonymous reviewers helped to significantly improve the manuscript.

Anthes, R. A.

Aonashi, K.

Bechtold, P., Bazile, E., Guichard, F., Mascart, P. and Richard, E.

Bielli, S. and Roux, F.

Bister, M. and Emanuel, K. A.

Black, M. L., Gamache, J. F., Marks, F. D. Jr, Samsury, C. E. and Willoughby, H. E.

Braun, S. A.

Burlaud, C., Viltard, N., Nuissier, O. and Roux, F.

Chen, Y. and Yau, M. K.

Chen, Y., Brunet, G. and Yau, M. K.

2002

\section{REFERENCES}

1972 The development of asymmetries in a three-dimensional numerical model of tropical cyclone. Mon. Weather Rev., 100, 461476

1993 An initialization method to incorporate precipitation data into a mesoscale numerical weather prediction model. J. Meteorol. Soc. Jpn., 71, 393-406

2001 A mass-flux convection scheme for regional and global models. Q. J. R. Meteorol. Soc., 127, 869-886

1999 Initialization of a cloud-resolving model with airborne Doppler radar observations of an oceanic tropical convective system. Mon. Weather Rev., 127, 1038-1055

1998 Dissipative heating and hurricane intensity. Meteorol. Atmos. Phys., 55, 233-240

2002 Eastern Pacific Hurricanes Jimena of 1991 and Olivia of 1994: The effect of vertical shear on structure and intensity. Mon. Weather Rev., 130, 2291-2312

2002 A cloud-resolving simulation of Hurricane Bob (1991): storm structure and eyewall buoyancy. Mon. Weather Rev., 130, $1573-1592$

'Numerical simulation and observations in passive microwave radiometry of the tropical Hurricane Bret (August 1999)'. Pp. 412-413 in Preprints 25th conference on hurricane and tropical meteorology, 29 April-3 May 2002. American Meteorological Society, San Diego, USA

Spiral bands in a simulated hurricane. Part I: Vortex Rossby wave verification. J. Atmos. Sci., 58, 2128-2145

2003 Spiral bands in a simulated hurricane. Part II: Vortex Rossby wave verification. J. Atmos. Sci., 60, 1239-1256 
Clark, T. L. and Farley, R. D.

Corbosiero, K. L. and Molinari, J.

Cuxart, J., Bougeault, Ph. and Redelsperger, J. L.

DeMaria, M.

Dupuis, H., Taylor, P. K., Weill, A. and Katsaros, $\mathrm{K}$.

Emanuel, K. A.

Fiorino, M. and Elsberry, R. L.

Frank, W. M. and Ritchie, E. A.

Franklin, J. L. and DeMaria, M.

Franklin, J. L., Lord, S. J., Feuer, S. E. and Marks, F. D. Jr.

Gal-Chen, T. and Sommerville, R. C. J.

Gamache, J. F., Willoughby, H. E., Black, M. L. and Samsury, C. E.

Guinn, T. A. and Schubert, W. H. Hawkins, H. F. and Imbembo, S. M.

Holland, G. J.

Jones, R. W.

Kain, J. S. and Fritsch, J. M.

Kain, J. S. and Fritsch, J. M.

Kossin, J. P. and Schubert, W. H.

Kuo, W.-H., Williams, R. T. and Chen, J. H.

Kurihara, Y. and Bender, M. A.

Kurihara, Y., Bender, M. A. and Ross, R. J.

Kurihara, Y., Bender, M. A., Tuleya, R. E. and Ross, R. J.

Lafore, J.-P., Stein, J., Ascencio, N., Bougeault, P., Ducrocq, V., Duron, J., Fisher, C., Hereil, P., Mascart, P., Pinty, J.-P., Redelsperger, J.-L., Richard, E. and Vila-Guerau de Arellano, J.

Lawrence, M. B., Avila, L. A., Beven, J. L., Franklin, J. L., Guiney, J. L. and Pasch, R. J.
Severe downslope windstorm calculation in two and three spatial dimensions using anelastic interactive grid nesting: A possible mechanism for gustiness. J. Atmos. Sci., 41, 329-350

The effect of vertical wind shear on the distribution of convection in tropical cyclones. Mon. Weather Rev., 130, 2110-2123

A turbulence scheme allowing for mesoscale and large-eddy simulations. Q. J. R. Meteorol. Soc., 126, 1-30

Tropical cyclone motion in a nondivergent barotropic model. Mon. Weather Rev., 113, 1199-1210

Inertial dissipation method applied to derive turbulent fluxes over the ocean during the Surface of the Ocean, Fluxes and Interactions with the Atmosphere/Atlantic Stratocumulus Transition Experiment (SOFIA/ASTEX) and Structures des Echanges Mer-Atmosphere, Proprietes des Heterogeneities Oceaniques: Recherche Experimentale (SEMAPHORE) experiments with low to moderate wind speeds. J. Geophys. Res., 102, 21115-21129

An air-sea interaction theory for tropical cyclones. Part I: Steadystate maintenance. J. Atmos. Sci., 43, 585-604

Some aspects of vortex structure related to tropical cyclone motion. J. Atmos. Sci., 46, 975-990

Effects of environmental flow upon tropical cyclone structure. Mon. Weather Rev., 127, 2044-2061

The impact of Omega dropsonde observations on barotropic hurricane-track forecasts. Mon. Weather Rev., 120, 381-391

The kinematic structure of Hurricane Gloria (1985) determined from nested analysis of dropwindsonde and Doppler radar data. Mon. Weather Rev., 121, 2433-2451

On the use of a coordinate transformation for the solution of the Navier-Stokes equations. J. Comput. Phys., 17, 209-228

'Wind shear, sea surface temperature, and convection in hurricanes observed by airborne Doppler radar'. Pp. 121-122 in Preprints 22nd conference on hurricane and tropical Meteorology. American Meteorological Society, Fort Collins, USA

Hurricane spiral bands. J. Atmos. Sci., 50, 3380-3403

The structure of a small, intense Hurricane Inez 1966. Mon. Weather Rev., 104, 418-442

An analytic model of the wind and pressure profile in hurricanes. Mon. Weather Rev., 108, 1212-1218

A nested grid for a three-dimensional model of tropical cyclone. J. Atmos. Sci., 34, 1528-1533

A one-dimensional entraining/detraining plume model and its application in convective parameterizations. J. Atmos. Sci., 47, 2784-2802

Convective parameterization for mesoscale models: The KainFritsch scheme. Meteorol. Monogr., 46, 165-170

Mesovortices, polygonal flow patterns, and rapid pressure falls in hurricane-like vortices. J. Atmos. Sci., 58, 2196-2209

1999 A possible mechanism for the eye rotation of Typhoon Herb. J. Atmos. Sci., 56, 1659-1673

1982 Structure and analysis of the eye of a numerically simulated tropical cyclone. J. Meteorol. Soc. Jpn., 60, 381-395

1993 An initialization scheme of hurricane models by vortex specification. Mon. Weather Rev., 121, 2030-2045

1995 Improvements in the GFDL hurricane prediction system. Mon. Weather Rev., 123, 2791-2801

1998 The Meso-NH atmospheric simulation system. Part I: Adiabatic formulation and control simulations. Ann. Geophys., 16, 90-109

2001 Atlantic hurricane season of 1999. Mon. Weather Rev., 129, 3057 3084 
Lewis, B. M. and Hawkins, H. F.

Lipps, F. B. and Hemler, R. S.

Liu, Y., Zhang, D. L. and Yau, M. K.

Mesinger, F. and Arakawa, A.

Moine, M.-P.

2001

Montgomery, M. T. and Kallenbach, R. J.

Morcrette, J.-J.

Muramatsu, T.

Nolan, D. S. and Montgomery, M. T.

Peng, M. S. and Williams, R. T.

$\mathrm{Pu}, \mathrm{Z}$. and Braun, S. A.

Pu, Z., Tao, W.-K., Braun, S., Simpson, J., Jia, J., Halverson, Y., Olson, W. and Hou, A.

Reasor, P. D., Montgomery, M. T., Marks, F. D. Jr. and

Gamache, J. F.

Richard, E., Cosma, S., Tabary, P., Pinty, J. P. and Hagen, M.

Rogers, R. F., Fritsch, J. M. and Lambert, W. C.

Rogers, R. F., Chen, S., Tenerelli, J. 2003 and Willoughby, $\mathrm{H}$.

Rotunno, R. and Emanuel, K. A.

Roux, F. and Marks, F. D. Jr.

Roux, F. and Viltard, N.

1995

Schubert, W. H.,

Montgomery, M. T.,

Taft, R. K., Guinn, T. A.,

Fulton, S. R., Kossin, J. P. and

Edwards, J. P.

Shapiro, L. J.

Shapiro, L. J. and

Montgomery, M. T.

2000

2003

2000
1982 Polygonal eyewalls and rainbands in hurricanes. Bull. Am. Meteorol. Soc., 63, 1294-1300

1982 A scale analysis of deep moist convection and some related numerical calculations. J. Atmos. Sci., 39, 2192-2210

1997 A multiscale numerical study of Hurricane Andrew (1992). Part I: Explicit simulation and verification. Mon. Weather Rev., 125, 3073-3093

1999 A multiscale numerical study of Hurricane Andrew (1992). Part II: Kinematics and inner-core structures. Mon. Weather Rev., 127, 2597-2616

1976 'Numerical methods used in atmospheric models'. GARP Tech. Rep. (WMO), 17, Vol. I. World Meteorological Organisation, Geneva, Switzerland

'Structure et évolution à mésoéchelle de perturbations cycloniques de l'Atlantique Nord pendant FASTEX'. Thesis, Université Paul Sabatier (available from Université Paul Sabatier, Toulouse III, Bureau du $3^{e}$ cycle, 118, Route de Narbonne, F-31062 Toulouse cedex 4, France)

1997 A theory for vortex Rossby-waves and its application to spiral bands and intensity changes in hurricanes. Q. J. R. Meteorol. Soc., 123, 435-465

1989 'Description of the radiation scheme in the ECMWF model'. ECMWF Tech. Memo. 117. Shinfield, Reading, UK

1986 The structure of the polygonal eye of a typhoon. J. Meteorol. Soc. Jpn., 64, 913-921

2002 Non-hydrostatic, three-dimensional perturbations to balanced, hurricane-like vortices. Part I: Linearized formulation, stability, and evolution. J. Atmos. Sci., 59, 2989-3020

1990 Dynamics of vortex asymmetries and their influence on vortex motion on a $\beta$ plane. J. Atmos. Sci., 47, 1987-2003

2001 Evaluation of bogus vortex techniques with four-dimensional variational data assimilation. Mon. Weather Rev., 129, 20232039

2002 The impact of TRMM data on mesoscale numerical simulation of supertyphoon Paka. Mon. Weather Rev., 130, 2448-2458

Low wave-number structure and evolution of the hurricane inner core observed by airborne dual-Doppler radar. Mon. Weather Rev., 128, 1653-1680

High-resolution numerical simulations of the convective system observed in the Lago Maggiore area on 17 September 1999 (MAP IOP 2a). Q. J. R. Meteorol. Soc., 129, 543-563

A simple technique for using radar data in the dynamic initialization of a mesoscale model. Mon. Weather Rev., 128, 25602574

A numerical study of the impact of vertical shear on the distribution of rainfall in Hurricane Bonny (1998). Mon. Weather Rev., 131, 1577-1599

1987 An air-sea interaction theory for tropical cyclones. Part II: Evolutionary study using a nonhydrostatic axisymmetric numerical model. J. Atmos. Sci., 44, 542-561

1996 Extended Velocity Track Display (EVTD): An improved processing method for Doppler radar observations of tropical cyclones. J. Atmos. Oceanic Technol., 13, 875-899

Structure and evolution of Hurricane Claudette on 7 September 1991 from airborne Doppler radar observations. Part I: Kinematics. Mon. Weather Rev., 123, 2611-2639

1999 Polygonal eyewalls, asymmetric eye contraction and potential vorticity mixing in hurricanes. J. Atmos. Sci., 56, 1197-1223

The asymmetric boundary layer flow under a translating hurricane. J. Atmos. Sci., 40, 1984-1998

1993 A three-dimensional balance theory for rapidly rotating vortices. J. Atmos. Sci., 50, 3322-3335 
Shapiro, L. J. and Ooyama, K. V.

Shapiro, L. J. and Willoughby, H. E. 1982

Smith, R. K., Ulrich, W. and Dietachmayer, G.

Stein, J., Richard, E., Lafore, J. P., Pinty, J. P., Asencio, N. and Cosma, S.

Takano, I. and Segami, A.

Tripoli, G. J.

Viltard, N. and Roux, F.

Wang, W. and Warner, T. T.

Wang, Y.

2001

Willoughby, H. E.

Willoughby, H. E., Clos, J. A. and Shoreibah, M. G.

Xiao, Q., Zou, X. and Wang, B.

Zhang, D.-L. and Altshuler, E.

Zhang, D.-L., Liu, Y. and Yau, M. K.

Zhu, T., Zhang, D.-L. and Weng, F.

Zou, X. and Xiao, Q.
Barotropic vortex evolution on a beta plane. J. Atmos. Sci., 47, $170-187$

The response of balanced hurricanes to local sources of heat and momentum. J. Atmos. Sci., 39, 378-394

A numerical study of tropical cyclone motion using a barotropic model. Part I: The role of vortex asymmetries. $Q$. J. $R$. Meteorol. Soc., 116, 337-362

Meso-NH simulations with grid-nesting and ice phase parameterization. Meteorol. Atmos. Phys., 72, 203-221

Assimilation and initialization of a mesoscale model for improved spin-up of precipitation. J. Meteorol. Soc. Jpn., 71, 377-391

An explicit three-dimensional nonhydrostatic numerical simulation of a tropical cyclone. Meteorol. Atmos. Phys., 49, 229254

Structure and evolution of Hurricane Claudette on 7 September 1991 from airborne Doppler radar observations. Part II: Thermodynamics. Mon. Weather Rev., 126, 3053-3067

Use of four-dimensional data assimilation by Newtonian relaxation and latent-heat forcing to improve a mesoscale-model precipitation forecast: A case study. Mon. Weather Rev., 116, 2593-2613

An explicit simulation of tropical cyclones with a triply nested movable mesh primitive equation model: TCM3. Part I: Model description and control experiment. Mon. Weather Rev., 129, 1370-1394

Vortex Rossby waves in a numerically simulated tropical cyclone. Part I: Overall structure, potential vorticity, and kinetic energy budgets. J. Atmos. Sci., 59, 1213-1238

Vortex Rossby waves in a numerically simulated tropical cyclone. Part I: The role in tropical cyclone structure and intensity changes. J. Atmos. Sci., 59, 1239-1262

Tropical cyclone eye thermodynamics. Mon. Weather Rev., 126, 3053-3067

Concentric eyewalls, secondary wind maxima, and the evolution of the hurricane vortex. J. Atmos. Sci., 39, 395-411

Initialization and simulation of a landfalling hurricane using a variational bogus-data assimilation scheme. Mon. Weather Rev., 128, 2252-2269

The effects of dissipative heating on hurricane intensity. Mon. Weather Rev., 127, 3032-3038

A multiscale numerical study of Hurricane Andrew (1992). Part III: Dynamically induced vertical motions. Mon. Weather Rev., 128, 3772-3788

A multiscale numerical study of Hurricane Andrew (1992). Part IV: Unbalanced flows. Mon. Weather Rev., 129, 92-107

A multiscale numerical study of Hurricane Andrew (1992). Part V: Inner-core thermodynamics. Mon. Weather Rev., 130, 27452763

Impact of Advanced Microwave Sounding Unit measurements on hurricane prediction. Mon. Weather Rev., 130, 2416-2432

2000 Studies on the initialization and simulation of a mature hurricane using a variational bogus-data assimilation scheme. J. Atmos. Sci., 57, 836-860 